Journal for ImmunoTherapy of Cancer

\title{
Bedside formulation of a personalized multi-neoantigen vaccine against mammary carcinoma
}

\author{
Mona O Mohsen (D) , ${ }^{1,2}$ Daniel E Speiser, ${ }^{3}$ Justine Michaux, ${ }^{4,5}$ HuiSong Pak, ${ }^{4,5}$ \\ Brian J Stevenson, ${ }^{6}$ Monique Vogel, ${ }^{2}$ Varghese Philipose Inchakalody, \\ Simone de Brot, ${ }^{7}$ Said Dermime (D) , ${ }^{8}$ Georges Coukos, ${ }^{5}$ \\ Michal Bassani-Sternberg, ${ }^{9,10}$ Martin F Bachmann ${ }^{2,11}$
}

To cite: Mohsen M0, Speiser DE, Michaux J, et al. Bedside formulation of a personalized multi-neoantigen vaccine against mammary carcinoma. Journal for ImmunoTherapy of Cancer 2022;10:e002927. doi:10.1136/ jitc-2021-002927

- Additional supplemental material is published online only. To view, please visit the journal online (http://dx.doi.org/10. 1136/jitc-2021-002927).

Accepted 29 November 2021

Check for updates

(c) Author(s) (or their employer(s)) 2022. Re-use permitted under CC BY-NC. No commercial re-use. See rights and permissions. Published by BMJ.

For numbered affiliations see end of article.

\section{Correspondence to} Dr Mona 0 Mohsen; mona.mohsen@dbmr.unibe.ch

Dr Michal Bassani-Sternberg; Michal.Bassani@chuv.ch

\section{ABSTRACT}

Background Harnessing the immune system to purposely recognize and destroy tumors represents a significant breakthrough in clinical oncology. Non-synonymous mutations (neoantigenic peptides) were identified as powerful cancer targets. This knowledge can be exploited for further improvements of active immunotherapies, including cancer vaccines, as T cells specific for neoantigens are not attenuated by immune tolerance mechanism and do not harm healthy tissues. The current study aimed at developing an optimized multitarget vaccine using short or long neoantigenic peptides utilizing virus-like particles (VLPs) as an efficient vaccine platform. Methods Mutations of murine mammary carcinoma cells were identified by integrating mass spectrometrybased immunopeptidomics and whole exome sequencing. Neoantigenic peptides were synthesized and covalently linked to virus-like nanoparticles using a Cu-free click chemistry method for easy preparation of vaccines against mouse mammary carcinoma.

Results As compared with short peptides, vaccination with long peptides was superior in the generation of neoantigen-specific $\mathrm{CD}^{+}$and $\mathrm{CD}^{+} \mathrm{T}$ cells, which readily produced interferon gamma (IFN- $\gamma$ ) and tumornecrosis factor $\alpha(\mathrm{TNF}-\alpha)$. The resulting anti-tumor effect was associated with favorable immune re-polarization in the tumor microenvironment through reduction of myeloid-derived suppressor cells. Vaccination with long neoantigenic peptides also decreased post-surgical tumor recurrence and metastases, and prolonged mouse survival, despite the tumor's low mutational burden.

Conclusion Integrating mass spectrometry-based immunopeptidomics and whole exome sequencing is an efficient approach for identifying neoantigenic peptides. Our multitarget VLP-based vaccine shows a promising anti-tumor effect in an aggressive murine mammary carcinoma model. Future clinical application using this strategy is readily feasible and practical, as click chemistry coupling of personalized synthetic peptides to the nanoparticles can be done at the bedside directly before injection.

\section{INTRODUCTION}

Driving the immune system to specifically recognize and destroy tumors represents a significant breakthrough in clinical oncology.
Non-synonymous mutations were identified as powerful cancer targets. This knowledge can be exploited for further improvements of active and passive immunotherapies, including cancer vaccines. $\mathrm{T}$ cells specific for neoantigenic peptides are typically not attenuated by immune tolerance mechanism and do not harm healthy tissues. ${ }^{1}$ Recent clinical trials have shown that de novo immune responses can be induced by vaccination with neoantigens in melanoma and glioblastoma patients. $^{2-5}$ The optimal peptide length for therapeutic cancer vaccines has been identified in preclinical and clinical studies. Short peptides of $\sim 8-11$ amino acids (a.a.) are the typical $\mathrm{CD}^{+} \mathrm{T}$ cell epitopes, while long peptides of $\sim 15-32$ a.a. contain both $\mathrm{CD}^{+}$ and $\mathrm{CD}^{+} \mathrm{T}$ cell epitopes. ${ }^{6}{ }^{7}$ Neoantigenic epitopes can be predicted based on their sequence, expression, proteasome cleavage sites, peptide abundance, major histocompatibility complex (MHC)-binding affinity and further physiochemical and structural features of peptide-MHC complexes. Long peptides are elongated at both ends with natural flanking residues that extend the repertoire of peptides binding to MHC-I to additional peptides binding MHC-II. Cytotoxic $\mathrm{CD}^{+}{ }^{+}$lymphocytes have been intensely characterized and identified as key players in anti-tumor immunity. Furthermore, $\mathrm{CD} 4^{+}$ $\mathrm{T}$ cells have recently emerged as important contributors in enhancing the immune response against tumors. ${ }^{89}$

There exist many different vaccine platforms, based on mRNA, peptides/proteins, dendritic cells (DCs) or recombinant viruses. ${ }^{10-13}$ Oncolytic viruses have been developed since many years, leading to the approval of talimogene laherparepvec (T-VEC) to treat patients with metastatic melanoma. ${ }^{14}$ The success of this therapy is likely related to the immunogenicity 
of T-VEC, which is particularly useful when injected directly into tumors, thus reaching the site(s) where the microenvironment must become more supportive and less suppressive for $\mathrm{T}$ cell responses. The intratumoral injection route has also become promising for treating patients with virus-like particles (VLPs) that carry CpGs oligodeoxynucleotides but no antigen, whereby the rational is that tumor antigens are present in the tumors, making it unnecessary to be provided as vaccine. The quasicrystalline VLPs are multiprotein complexes with a highly defined repetitive surface geometry, mostly in the shape of an icosahedrons. ${ }^{15}$ Epitope repetitiveness serves as a potent pathogen-associated structural pattern (PASP) efficiently recognized by innate and adaptive immune cells. ${ }^{16}$ The outer surface of VLPs can be decorated with antigenic peptides. Inside of the VLPs, one can package innate immune stimulators such as toll-like receptor (TLR) ligands for efficient cellular activation. ${ }^{15}$ VLPs built with bacteriophage $Q \beta$ protein (Qß-VLPs) are highly immunogenic and very versatile for the production of vaccine candidates with antigens and innate immune stimulators. In our earlier studies and clinical trials, we showed that such VLP vaccines induced strong tumor antigen-specific $\mathrm{T}$ cell responses in preclinical models and melanoma patients. ${ }^{17} 18$ Our $\mathrm{Q} \beta$ (G10)-Melan-A vaccine was based on Q $\beta$-VLPs packaged with G10, a TLR-9 ligand inducing a potent interferon (IFN) $\alpha$ response, ${ }^{19}$ and decorated with a long peptide derived from the Melan- $\mathrm{A}^{\text {Martl }}$ melanoma differentiation antigen. Chemical coupling of peptides to the $Q \beta-V L P s$ was performed using the (succinimidyl-6-((bmaleimidopropionamido)hexanoate) SMPH bifunctional cross-linker. Clinical trials showed that more than half of patients with stage II-IV melanoma generated strong tumor antigen-specific and in vivo functional $\mathrm{CD}^{+}$and $\mathrm{CD} 4^{+} \mathrm{T}$ cell responses. ${ }^{20}$ The tumors of some patients showed late loss of Melan-A expression, indicating that targeting of only a single antigen is problematic because of disease progression caused by antigen-loss variants. Indeed, preclinical models confirmed that targeting multiple antigens is superior in generating $\mathrm{CD}^{+}$and $\mathrm{CD} 8^{+} \mathrm{T}$ cell responses that can successfully infiltrate tumors, control tumor growth and avoid outgrowth of escape variants. ${ }^{21}$

The current study aimed at developing an optimized anti-tumor vaccine using short or long neoantigenic peptides. VLPs were packaged with a TLR-9 ligand and decorated with neoantigenic peptides discovered by peptidomic, genetic and transcriptomic techniques. Vaccines were composed of mixtures of four VLPs each with a different peptide, coupled by click chemistry permitting easy patient-individual vaccine preparation at the bedside. Our study provides proof of concept of an effective personalized therapeutic cancer vaccine that can readily be implemented for clinical use.

\section{MATERIALS AND METHODS}

\section{Production and purification of Q $\beta$-VLPS}

The expression and production of the bacteriophage $\mathrm{Q} \beta$-VLPs were carried out as previously described. ${ }^{22-24}$

\section{Cell lines and mice}

4T1 mammary carcinoma cell line (ATCC CRL-2539) and EpH4-Ev wild-type mammary epithelial cell line (ATCC CRL-3063) were cultured in Gibco Dulbecco's Modified Eagle Medium (DMEM) medium supplemented with $10 \%$ fetal bovine serum (FBS) and $1 \%$ penicillin/streptomycin. For EpH4-Ev cell line, $6 \mu \mathrm{g}$ puromycin was added to the culture medium as per ATCC instructions. When cells were $80 \%$ confluent, medium was aspirated and cells were washed $3 \times$ with $1 \times$ phosphate-buffered saline (PBS) to remove excess medium. $1 \times$ trypsin was added and flasks were incubated at $37^{\circ} \mathrm{C}$ for $10 \mathrm{~min}$. Cells were collected, resuspended in complete medium and kept on ice until use. Mycoplasma contamination was ruled out using Microsart AMP Mycoplasma Kit. Wild-type female Balb/cOlaHsd mice (8-12 weeks) were purchased from Harlan and kept in the animal facility at the University of Bern. $1 \times 10^{6}$ cells were inoculated subcutaneously (s.c.) in the flank region under isoflurane anesthesia. All animal procedures were conducted in accordance with the Swiss Animal Act (455.109.1—September 2008, 5) of University of Bern.

\section{DNA sequencing and prediction of non-synonymous mutations}

DNA was extracted using the commercially available Purelink Genomic DNA mini kit (Invitrogen) as per the manufacturer's instructions. The purity and concentration of the DNA of both cell lines were measured using nanodrop. Whole exome sequencing (WES) was performed on an Illumina HiSeq 4000 machine using libraries prepared with a SureSelectXT Mouse All Exon capture kit (Agilent Technologies, Santa Clara, California, USA), to produce 150 paired end reads sufficient for a mean bait coverage of at least $150 \times$. The sequence reads were aligned to the GRCm38.p6 mouse reference assembly using BWA-MEM V.0.7.17, ${ }^{25}$ and variants were predicted using the Genome Analysis Toolkit best practices protocol (GATK V.3.7). A set of reference variants for mouse was derived from data generated by the Wellcome Sanger Institute Mouse Genomes Project (available at ftp://ftp-mouse.sanger. ac.uk/REL-1807-SNPs_Indels/). Somatic mutations (SMs) were defined as variants present only in the 4T1 sample, while single nucleotide polymorphisms (SNPs) were defined as variants present in both the 4T1 and EpH4-Ev samples. The functional effect of the predicted SMs and SNPs was determined by annotating the variants with snpEff V.4.3T ${ }^{26}$ using the GRCm38.86 and mm10 databases.

\section{Purification of MHC-I binding peptides}

Anti-MHC-I monoclonal antibodies were purified from the supernatant of HIB 34.1.2 hybridoma cells (a gift from Angel Miguel Garcia-Lora, Hospital Universitario Virgen de las Nieves, Granada, Spain) using Protein A-Sepharose 4B beads (Invitrogen). Antibodies were cross-linked to Protein A-Sepharose 4B beads at a concentration of $5 \mathrm{mg}$ of antibodies per $1 \mathrm{~mL}$ volume of beads at room 
temperature (RT) with dimethyl pimelimidate dihydrochloride (Sigma-Aldrich) in $0.2 \mathrm{M}$ sodium borate buffer pH 9 (Sigma-Aldrich) at a final concentration of $20 \mathrm{mM}$ for $30 \mathrm{~min}$. $2.33 \times 10^{8} 4 \mathrm{~T} 1$ cells grown in culture or $8 \times 10^{8}$ grown in vivo in Balb/c mice per replicate were lysed in phosphate buffered saline containing $0.2 \mathrm{mM}$ iodoacetamide (Sigma-Aldrich), $1 \mathrm{mM}$ EDTA, 1:200 Protease Inhibitor Cocktail (Sigma-Aldrich), 0.5\% sodium deoxycholate (Sigma-Aldrich), 1\% octyl- $\beta$-D-glucopyranoside (Sigma-Alrich) and $1 \mathrm{mM}$ phenylmethylsulfonylfluoride (Roche) at $4^{\circ} \mathrm{C}$ for 1 hour. Lysates were cleared by centrifugation at $4^{\circ} \mathrm{C}$ at $20000 \mathrm{~g}$ for $50 \mathrm{~min}$. MHC-I molecules were purified by incubating the cleared lysate with HIB antibodies cross-linked to Protein A-Sepharose 4B beads in affinity columns for 3 hours at $4^{\circ} \mathrm{C}$. The affinity columns were washed first with $150 \mathrm{mM}$ sodium chloride $(\mathrm{NaCl})$ in $20 \mathrm{mM}$ Tris- $\mathrm{HCl} \mathrm{pH} 8$, then with $400 \mathrm{mM} \mathrm{NaCl}$ in $20 \mathrm{mM}$ Tris- $\mathrm{HCl} \mathrm{pH} 8$ and again with $150 \mathrm{mM} \mathrm{NaCl}$ in $20 \mathrm{mM}$ Tris-HCl pH 8 . The beads were washed with $20 \mathrm{mM}$ Tris-HCl pH 8 and the MHC complexes were eluted by adding $1 \%$ trifluoroacetic acid (TFA) at RT. For the purification and concentration of MHC peptides, Sep-Pak tC18 96-well plates (Waters) were preconditioned with $80 \%$ acetonitrile (ACN) in $0.1 \%$ TFA and wahsed with $0.1 \%$ TFA. Elutions were loaded in the Sep-Pak tC18 96-well plates and the C18 wells were then washed with $0.1 \%$ TFA. The peptides were eluted with $28 \%$ ACN in $0.1 \%$ TFA. The peptide samples were dried using vacuum centrifugation (Thermo Fisher Scientific) and stored at $-20^{\circ} \mathrm{C}$.

\section{Liquid chromatography and mass spectrometry}

Peptides were separated on a $450 \mathrm{~mm}$ analytical column (8 $\mu \mathrm{m}$ tip, $75 \mu \mathrm{m}$ inner diameter, PicoTipTMEmitter, New Objective) packed with ReproSil-Pur C18 (1.9 $\mu \mathrm{m}$ particles, $120 \AA$ pore size, Dr Maisch GmbH) with an Easy-nLC 1200 (Thermo Fisher Scientific). The separation was performed at a flow rate of $250 \mathrm{~nL} / \mathrm{min}$ by a gradient of $0.1 \%$ formic acid (FA) in $80 \%$ ACN (solvent B) and $0.1 \%$ FA in water (solvent A). With a $Q$ Exactive HF-X mass spectrometer (Thermo Fisher Scientific), MS1 spectra were acquired from $\mathrm{m} / \mathrm{z}=300-1650$ with a resolution of $60,000(\mathrm{~m} / \mathrm{z}=200)$, an ion accumulation time of $80 \mathrm{~ms}$ and an auto gain control (AGC) was set to $3 \mathrm{e} 6$ ions. MS/ MS spectra were acquired in a data-dependent manner on the 10 most abundant precursor ions with a resolution of 15,000 (m/z=200), an ion accumulation time of 120 $\mathrm{ms}$ and an isolation window of $1.2 \mathrm{~m} / \mathrm{z}$. The AGC was set to $2 \mathrm{e} 5$ ions. The dynamic exclusion was set to $20 \mathrm{~s}$ and a normalized collision energy of 27 was used.

\section{Identification of neoantigenic peptides from MS immunopeptidomic data}

Non-synonymous SMs and SNPs were incorporated into the headers of reference protein Fasta as previously described. ${ }^{27}$ Mouse GENCODE sequences and the associated gene annotations (V.M22; reference assembly V.GRCm38 from https://www.gencodegenes. org/mouse/releases.html) were scanned for the presence of 4T1-specific variants using genomic coordinates from the transcript annotations. Variants producing non-synonymous changes were identified and the corresponding a.a. changes were tagged with a unique ID and added to the header of the translated transcript sequence. We searched the immunopeptidomic MS data against the 4T1-specific customized reference database with MaxQuant V.1.5.9.4. ${ }^{28}$ The default settings were used except and in addition the following settings were included: variants were called from file, methionine oxidation and protein N-term acetylation were set as variable modifications and no fixed modification was set, enzyme specificity was set to 'unspecific' and peptide spectrum match false discovery rate (FDR) was set to 0.05 with no protein FDR. Binding affinity of the peptides to the MHC molecules was predicted by NetMHCpan V.4.1 software. ${ }^{29}$ Binding motif deconvolution of 9-mer MHC-I peptides was performed using the MixMHCp 2.1 ${ }^{3031}$ with the default settings and deconvoluted motifs were manually assigned as $\mathrm{H}-2-\mathrm{D}^{\mathrm{d}}$ and $\mathrm{H}-2-\mathrm{K}^{\mathrm{d}}$.

\section{Verification of identified NeoAG}

To verify the expression of the identified NeoAG, RNA from 4T1 mammary carcinoma cell line, 4T1 established tumor and EpH4-Ev wild-type mammary epithelial cell line were extracted using NucleoSpin RNA Kit and reverse transcribed using High-Capacity RNA-to-cDNA Kit as per the manufacturer's instructions. Three primer pairs were designed of $\sim 24 \mathrm{bp}$ each, to amplify the mutated region leading to three amplicons of $\sim 200 \mathrm{bp}$ each. The PCR products were electrophoresed and after gel extraction, the amplicons with the expected size were purified using Zymoclean Gel DNA Recovery Kit. Amplicons were then sequenced using Sanger sequencing with the primers used for PCR amplification. The results confirmed the somatic missense mutations in 4T1 mammary carcinoma cell line and the established 4T1 tumors in Balb/c mice; however, these mutations were absent from the wild-type control mammary epithelial cell line.

\section{Synthesis of neoantigenic peptides (short and long)}

The identified NeoAG in 4T1 mammary carcinoma cell line were synthesized as short (15-16a.a.) or long (32a.a.) peptides using their flanking regions as listed in table 1.

An additional lysine (K) and an azide group (N3) were added at the C-terminus of the synthesized peptides to facilitate $\mathrm{Cu}$-free click chemistry coupling. Neoantigenic short and long peptides are referred to as $\mathrm{NeoAG}_{\mathrm{S}}$ and $\mathrm{NeoAG}_{\mathrm{L}}$, respectively. Neoantigenic MHC-I peptides (8 a.a. or 9 a.a. underlined), non-synonymous SMs (in bold) .

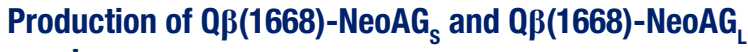 vaccines}

The naturally packaged single-stranded RNA (ssRNA) in $Q \beta$-VLPs was digested as following: $Q \beta$ (ssRNA)-VLPs were washed $3 \times$ with $20 \mathrm{mM}$ HEPES (Sigma-Aldrich) using Amicon-Ultra $0.5 \mathrm{~mL}$ tubes $100 \mathrm{kDa}$ molecular weight 
Table 1 Synthesized neoantigenic peptides (NeoAG) with flanking regions, additional lysine and an azide group (N3) at the C-terminus

\begin{tabular}{llll}
\hline NeoAG & $\begin{array}{l}\text { Class I epitope } \\
\text { sequence }\end{array}$ & $\begin{array}{l}\text { Neoantigenic short peptide } \\
\text { (NeoAG }_{\mathbf{s}} \text { ), 15-16 mers }\end{array}$ & $\begin{array}{l}\text { Neoantigenic long peptide } \\
\text { (NeoAG }), 32 \text { mers }\end{array}$ \\
\hline NeoAG 1 & KYLDSPKRL & QKQKYLDSPKRLVGLK(N3) & PNTEKITRQKQKYLDSPKRLVGLCGRWNKASK(N3) \\
NeoAG 2 & SPKRLVGL & YLDSPKRLVGLCGRK(N3) & KITRQKQKYLDSPKRLVGLCGRWNKASETLK(N3) \\
NeoAG 3 & KYNAVPTVF & KNLKYNAVPTVFAFQK(N3) & CFSAFGNRKNLKYNAVPTVFAFQNPTEVCPEK(N3) \\
NeoAG 4 & VYREQMNGV & FDSVYREQMNGVQRFK(N3) & FTVAQSEAFDSVYREQMNGVQRFPWDTSEEDK(N3) \\
\hline
\end{tabular}

NeoAG, neoantigen.

cut-off (MWCO). RNAse A (Merck) was used to digest the ssRNA $(1.2 \mathrm{mg} / \mathrm{mL}$ for each $3 \mathrm{mg} / \mathrm{mL}$ Q $\beta$-VLPs $)$ and incubated at $37^{\circ} \mathrm{C}$ for 3 hours in a shaker at $400 \mathrm{rpm}$. The digestion of the ssRNA was confirmed by $1 \%$ agarose gel stained with SYBR Safe dye for $30 \mathrm{~min}$ at $90 \mathrm{~V}$. Q $\beta$-VLPs were then re-packaged with B-type 1668 CpGs $\left(5^{\prime \prime}\right.$-TCC ATG ACG TTC CTG ATG CT-3") with phosphorothioate backbone purchased from Invitrogen. The re-packaging was confirmed by $1 \%$ agarose gel stained with SYBR Safe dye for $30 \mathrm{~min}$ at $90 \mathrm{~V}$. The presence of $Q \beta(1668)$-VLPs protein was detected by staining the $1 \%$ agarose gel with Coomassie Blue stain. $Q \beta(1668)$-VLPs were then derivatized for $30 \mathrm{~min}$ at RT using dibenzocyclooctyne NHS ester (DBCO cross-linker) (Sigma-Aldrich) in a fivefold molar excess. Amicon-Ultra $0.5 \mathrm{~mL}$ tubes $100 \mathrm{kDa}$ MWCO were used to remove excess DBCO cross-linker. The $\mathrm{NeoAG}_{\mathrm{S}}$ or $\mathrm{NeoAG}_{\mathrm{L}}$ peptides were synthesized by Pepscan BRESTO with the addition of lysine (K) and (N3) azide group at the C-terminus to facilitate their coupling to the derivatized $Q \beta(1668)-V L P s$. The synthesized peptides were reconstituted in Dimethyl sulfoxide (DMSO) and added in a fourfold molar excess over $Q \beta(1668)$-VLPs monomer. The vaccine was incubated 1 hour at RT and Amicon-Ultra $0.5 \mathrm{~mL}$ tubes $100 \mathrm{kDa} \mathrm{MWCO}$ were used to remove excess peptide. The coupling of the $\mathrm{NeoAG}_{\mathrm{S}}$ or $\mathrm{NeoAG}_{\mathrm{L}}$ to $\mathrm{Q} \beta(1668)$-VLPs was done separately for each neoantigenic peptide. The efficiency of the coupling was checked with SDS-PAGE (BIO-RAD).

\section{Vaccination of mice}

Balb/c mice were vaccinated after inoculation of $4 \mathrm{~T} 1$ mammary carcinoma cell line as described in the Cell lines and mice section. Designed groups, vaccination doses and regimen were scheduled as described in the Results section. Briefly, we injected $1 \times 10^{6} 4 \mathrm{~T} 1$ s.c. in the flank as previous studies have shown that this method possesses an increased localization of the primary tumor, which makes it easier to be resected in surgery. Injecting 4T1 in mammary fat or orthotopically showed enhanced invasive growth pattern. The s.c. inoculation method of $4 \mathrm{~T} 1$ results in metastases as per our primary data and as shown by other studies. ${ }^{32}$ Vaccination using s.c. injection (over the shoulders, into the loose skin over the neck) started 3 days after cell line inoculation as summarized in table 2. Mice were followed every 2 days to assess tumor volume and general health score. Three doses (PrimeBoost-Boost) of the vaccine $(40 \mu \mathrm{g}$ each dose) were administered over 17 days (please refer to the Efficient coupling of synthetic NeoAG peptides by Cu-free click chemistry to VLPs section). Tumors in the control group reached the ethically maximal tolerated size of $1 \mathrm{~cm}^{3}$ by day 17. For the experiment in the Long peptide vaccination decreases post-surgical tumor recurrence and lung metastases, and prolongs survival section, primary tumors were resected on day 14 from all groups and 2 vaccine doses were administered weekly. Mice weight was followed

Table 2 Treatment groups and vaccine doses

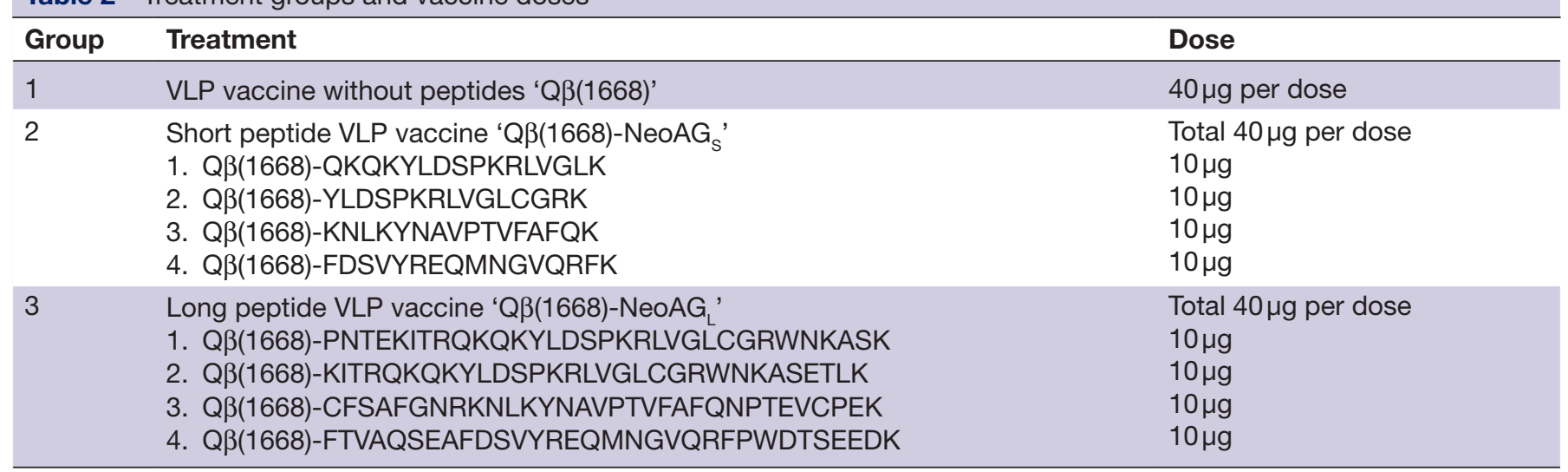

VLP, virus-like particle. 
routinely and were euthanized when loosing 10\%-15\% of their original weight. Lungs were collected when mice were euthanized and lung weight was measured.

\section{Analysis of blood cells}

Blood was collected from mice' tail vein on day 16 after inoculation of 4T1 mammary carcinoma. One hundred and fiftymicroliters of blood was collected in $500 \mu \mathrm{L}$ $1 \times$ PBS containing heparin and kept on ice. Cells were centrifuged at $1200 \mathrm{rpm}$ for $5 \mathrm{~min}$ and supernatant was aspirated. RBCs were lysed using $500 \mu \mathrm{L}$ (AmmoniumChloride-Potassium) ACK buffer (Sigma-Aldrich) on ice for 2-3 min. White blood cells were collected after $5 \mathrm{~min}$ of centrifugation at $1200 \mathrm{rpm}$. Supernatant was aspirated and cells were resuspended with $1 \times$ PBS containing $0.1 \%$ Bovine serum albumin (BSA) and again centrifuged. Pelleted cells were labeled with live/dead stain, antimouse CD16/CD32 (mouse BD Fc block) mAb clone 2.4G2 (BD Bioscience) for $10 \mathrm{~min}$ in the dark, centrifuged as described above and stained with $\mathrm{PE}$ anti-mouse CD8 $\alpha$ mAb clone 53-6.7 (BD Bioscience), PE/Cyanine7 anti-mouse $\mathrm{CD} 4 \mathrm{mAb}$ clone RM4-5 (BioLegend), APC anti-mouse Ly6G mAb clone 1A8 (BioLegend), FITC anti-mouse Ly6C clone HK1.4 (BioLegend) and APC/ Cyanine7 anti-mouse CD11b clone M/170 (BioLegend). Samples were read by FACSCaliber and analysis was done using GraphPad Prism V.8.4.2 (464). Gating for monocytic $\left(\mathrm{CD} 11 \mathrm{~b}^{\mathrm{Hi}} \mathrm{Ly}_{6 \mathrm{C}^{\mathrm{Hi}}}\right)$ and granulocytic $\left(\mathrm{CD} 11 \mathrm{~b}^{\mathrm{Hi}}\right.$ Ly6 $\mathrm{G}^{\mathrm{Hi}}$ ) myeloid-derived suppressor cells (MDSCs) was carried out as illustrated in online supplemental figure 1.

To assess the immunogenicity of the single NeoAG, mice were vaccinated on day 0 s.c. with $40 \mu$ g of $Q \beta(1668)$ $\mathrm{NeoAG}_{\mathrm{L}-1}$ or $\mathrm{Q} \beta(1668)-\mathrm{Neo}_{\mathrm{L}-2}$ or $\mathrm{Q} \beta(1668)-\mathrm{NeoAG}_{\mathrm{L}-3}$ or $Q \beta(1668)-\mathrm{NeoAG}_{\mathrm{L}-4}$ separately or with the multitarget vaccine $\mathrm{Q} \beta(1668)-\mathrm{NeoAG}_{\mathrm{L}}$. Splenocytes were collected 7 days later for intracellular cytokine staining. Naïve mice and a control peptide (CP) were used.

\section{Analysis of tumors}

Tumors were measured every 3 days using a caliper using the formula $\mathrm{V}=(\mathrm{W} \times \mathrm{WxL}) / 2, \mathrm{~V}=$ final tumor volume in $\mathrm{mm}^{3}, \mathrm{~L}=$ tumor length and $\mathrm{W}=$ tumor width. On day 17 , mice were euthanised as tumors in the control group reached the size of $1 \mathrm{~cm}^{3}$. Tumors were collected in DMEM medium containing $10 \%$ FBS and $1 \%$ penicillin/ streptomycin on ice. Tumor infiltrating lymphocytes (TILs) were collected as following: tumors were dissected into pieces and smashed using $70 \mu \mathrm{M}$ cell strainer, cells were washed during the process using DMEM medium containing $10 \% \mathrm{FBS}$ and $1 \%$ penicillin/streptomycin in $50 \mathrm{~mL}$ falcon tubes. Collected cells were added to $15 \mathrm{~mL}$ tubes containing $2 \mathrm{~mL}$ of $35 \%$ Percoll slowly. The tubes were centrifuged at $1800 \mathrm{rpm}$ for $25 \mathrm{~min}$ at RT to isolate TILs. TILs were then resuspended in $200 \mu \mathrm{L}$ PBS $(0.1 \%$ BSA) and $100 \mu \mathrm{L}$ was transferred to 96-well v-bottom plates and centrifuged at $1200 \mathrm{rpm}$ for $5 \mathrm{~min}$. Supernatant was discarded, and RBCs were lysed using ACK $500 \mu \mathrm{L}$ ACK buffer on ice for 2-3 min. TILs were stained with live/dead, anti-mouse CD16/CD32 (mouse BD Fc block) $\mathrm{mAb}$ clone $2.4 \mathrm{G} 2$ for $10 \mathrm{~min}$ in the dark, centrifuged as described above and stained with $\mathrm{PE}$ anti-mouse $\mathrm{CD} 8 \alpha$ $\mathrm{mAb}$ clone 53-6.7 and $\mathrm{PE} /$ Cyanine7 anti-mouse CD4 $\mathrm{mAb}$ clone RM4-5. In the second experiment, TILs were also stained with APC anti-mouse Ly6G mAb clone 1A8, FITC anti-mouse Ly6C clone HK1.4 and APC/Cyanine7 anti-mouse CD11b clone M/170. Plates were centrifuged at $1200 \mathrm{rpm}$ for $5 \mathrm{~min}$, supernatant was discarded, TILs were resuspended in PBS (0.1\% BSA) and added to $5 \mathrm{~mL}$ round-bottom tubes with cell strainer to remove excess tumor debris. Samples were read by FACSCaliber and analysis was done using GraphPad Prism V.8.4.2 (464).

\section{Intracellular cytokine staining}

One hundred microliters of the TILs described in the Analysis of tumors section were transferred to sterile 96-well flat-bottom plates. TILs were additionally incubated with mouse IL-2 (mIL2-Ref: 11271164001-MERCK) 100U/mL in DMEM medium containing $10 \%$ FBS and $1 \%$ penicillin/ streptomycin at $37^{\circ} \mathrm{C}$ for 2 days. Cells were washed $3 \times$ with DMEM medium containing 10\% FBS and $1 \%$ penicillin/ streptomycin and a stimulation cocktail was added to $1 \mu \mathrm{g} /$ $\mathrm{mL}$ of each NeoAG with Brefeldin and Monensin (1:1000) at $37^{\circ} \mathrm{C}$ for 6 hours. TILs were washed $3 \times$ with DMEM medium to remove the stimulation cocktail and then transferred to 96-well v-bottom plates for staining. TILs were stained with live/dead, anti-mouse CD16/CD32 (mouse BD Fc block) $\mathrm{mAb}$ clone $2.4 \mathrm{G} 2$ for $10 \mathrm{~min}$ in the dark, centrifuged as described above and stained with PE anti-mouse CD $8 \alpha \mathrm{mAb}$ clone 53-6.7 and PE/Cyanine7 anti-mouse CD4 mAb clone RM4-5. The plates were centrifuged at $1200 \mathrm{rpm}$ for $5 \mathrm{~min}$, supernatant was discarded and TILs were fixed using $100 \mu \mathrm{L}$ of the fixation buffer (BD Cytofix) at $4^{\circ} \mathrm{C}$ for $15 \mathrm{~min}$. The plates were again centrifuged at $1200 \mathrm{rpm}$ for $5 \mathrm{~min}$, supernatant was discarded and TILs were washed with $100 \mu l$ of $1 \times$ diluted permeabilization wash buffer (BioLegend) and centrifuged immediately at $1200 \mathrm{rpm}$ for $5 \mathrm{~min}$, supernatant was discarded. TILs were then stained with APC anti-mouse IFN- $\gamma$ mAb clone XMG1.2 (MERCK) and PerCP-Cyanine5.5 anti-mouse TNF- $\alpha$ mAb clone MP6-XT22 (BioLegend). Plates were centrifuged at $1200 \mathrm{rpm}$ for $5 \mathrm{~min}$, supernatant was discarded, TILs were resuspended in PBS (0.1\% BSA) and added to $5 \mathrm{~mL}$ round-bottom tubes with cell strainer to remove excess tumor debris. For splenocytes, $2 \times 10^{6}$ cells were used and a similar protocol was followed. The stimulation cocktail consists of $1 \mu \mathrm{g} / \mathrm{mL}$ of each NeoAG separately or combined. Samples were read by FACSCaliber and analysis was done using GraphPad Prism V.8.4.2 (464).

\section{Immunohistochemistry}

Formalin-fixed murine mammary carcinomas were assessed by immunohistochemistry (IHC) staining for $\mathrm{CD}^{+}$and $\mathrm{CD}^{+} \mathrm{T}$ cells using CD4 (clone 4SM95, rat, Thermo F. Scientific, 14-9766) and CD8 (rat, Dianova, DIA-808). For each tumor, one full cross-section was examined by a boardcertified veterinary pathologist $(\mathrm{SdB})$. The quantitative evaluation of peritumoral and intratumoral $\mathrm{CD} 4^{+}$and $\mathrm{CD} 8^{+} \mathrm{T}$ 
cells was done digitally using the software QuPath V.0.2.3. The number of $\mathrm{CD}^{+}$and $\mathrm{CD}^{+} \mathrm{T}$ cells was calculated per $\mathrm{mm}$ (tumor periphery) and per $\mathrm{mm}^{2}$ (intratumoral area).

\section{In vivo depletion of $\mathrm{CD8}^{+} \mathrm{T}$ cell}

For depletion of $\mathrm{CD}^{+} \mathrm{T}$ cells, $200 \mu \mathrm{g}$ anti-CD8mAb (BioXcell clone CD8 $\beta$ Lyt3.2) was administered intraperitoneally on day 1 and $100 \mu \mathrm{g}$ every week after inoculation of $4 \mathrm{~T} 1$ mammary carcinoma. Depletion efficiency was $\sim 99 \%$ as determined by flow cytometry on day 3 and day 12. Flow cytometry was performed as explained in the Analysis of blood cells section.

\section{Statistics}

Data were presented as mean \pm SEM. Comparisons between two groups was performed by Student's unpaired $t$ test (twotailed). Comparison between more than two groups was performed by one-way ANOVA or Bonferroni test. Area under curve (AUC) was used to measure tumor growth curves. Survival rate was analyzed by log-rank (Mantel-Cox) test. P values were $* * * * \mathrm{p}<0.0001$; $* * * \mathrm{p}<0.001 ; * * \mathrm{p}<0.01$; $* \mathrm{p}<0.05$.

\section{RESULTS}

\section{NeoAG identification}

The current study aimed at providing a proof of concept (POC) for the generation of a personalized VLP-based vaccine by incorporating tumor-specific NeoAG of mammary carcinoma. We have chosen the aggressive, highly metastatic and low mutational burden mammary carcinoma cell line (4T1). ${ }^{11}$ The wild-type mammary epithelial cell line, EpH4$\mathrm{Ev}$, was selected as germline reference cells. Both cell lines originate from Balb/c mice. NeoAG identification was performed by WES combined with immunopeptidomics (figure 1A). MHC-I binding peptides were eluted from 4T1 cells and were characterized by LC-MSMS. A 4T1-specific reference database that includes non-synonymous SMs was generated to match the MSMS data. In total, 2714 and 5077 MHC-I peptides were identified in the $4 \mathrm{~T} 1$ mammary carcinoma cells grown in vitro and in vivo, respectively (online supplemental data 1). The peptides recapitulated the expected length distribution of MHC-I ligands, meaning the majority were 9 mers, and the 9-mer peptides were clustered into two groups, revealing the expected binding motifs of $\mathrm{H}-2-\mathrm{D}^{\mathrm{d}}$ and $\mathrm{H}-2-\mathrm{K}^{\mathrm{d}}$ (figure 1B-D). Despite the low mutational burden of 4T1, we identified four NeoAG by MSMS (figure $1 \mathrm{E}-\mathrm{H})$. The non-synonymous SMs were identified in Vrk3 (E391K), Thap3 (H75Y) and Sult2b1 (H299N) as shown in figure 1 and online supplemental table 1.

\section{Verification of NeoAG sequence and expression}

We performed RT-PCR to verify the sequence and expression of the NeoAG. RNA was extracted from the 4T1 mammary carcinoma cell line, from $4 \mathrm{~T} 1$ tumor in vivo and from the EpH4-Ev wild-type mammary epithelial cell line as control. The results confirmed presence and expression of the nonsynonymous SMs in 4T1 mammary carcinoma cell line as well as in $4 \mathrm{~T} 1$ tumor in vivo in Balb/c mice. These mutations were absent in EpH4-Ev cells (online supplemental figure 2).

\section{Efficient coupling of synthetic NeoAG peptides by Cu-free click chemistry to VLPs}

$\mathrm{Q} \beta($ ssRNA)-VLPs were expressed and purified as described previously. ${ }^{22} 23$ The integrity of $Q \beta($ ssRNA)-VLPs was confirmed by electron microscopy (figure 2A). In a next step, $\mathrm{Q} \beta$ (ssRNA)-VLPs were treated with RNaseA to digest the RNA that was naturally packaged during protein expression in Escherichia coli. ${ }^{153}$ The empty particles were then re-packaged with the B-type CpGs 1668, a TLR-9 ligand and potent activator of DCs, required for effective DC maturation and cross-priming. The re-packaging is based on direct diffusion of $\mathrm{CpG}$ into $\mathrm{Q} \beta$-VLPs via its natural pores followed by binding to arginine repeats inside the capsid which in the natural virus are binding the viral genome. ${ }^{34}$ The re-packaging process of $Q \beta$-VLPs with the CpGs was confirmed in a $1 \%$ agarose gel stained with SYBR Safe dye (figure 2B, top), and the presence of the VLP's capsid protein was assessed by staining the agarose gel with Coomassie Blue (figure 2B, bottom). In two previous and independent studies, we have shown that the bio-orthogonal $\mathrm{Cu}$-free click chemistry is an efficient, safe (non-toxic) and fast method to chemically couple peptides of 14 a.a. to Q $\beta$-VLPs ${ }^{21}$ or to the plantderived virus $\mathrm{CuMV}_{\mathrm{TT}}$-VLPs. ${ }^{35}$ For several reasons, including ease of manufacturing and safety, this method is preferable over using the heterobifunctional cross-linker SMPH when considering the development of a personalized cancer vaccine (see also the Discussion section). Short (15-16a.a.) or long (32a.a.) neoantigenic peptides were synthesized with an additional lysine (K) and an azide group (N3) at the C-terminus (table 1) for coupling to $Q \beta(1668)$-VLPs (table 2). The coupling efficiency was confirmed by SDS-PAGE followed by densitometric analysis. SDS-PAGE showed Q $\beta$-VLP monomers $(\sim 14 \mathrm{kDa})$ as well as additional bands, indicating effective coupling of the synthesized NeoAG to $Q \beta(1668)$-VLPs (figure 2C). Densitometric analysis of $\mathrm{Q} \beta(1668)$ alone,

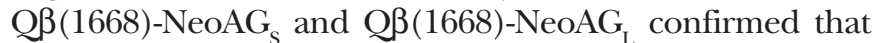
the coupling was efficient (data not shown). Each NeoAG peptide (short or long) was coupled to $Q \beta(1668)$-VLPs separately. To avoid possible outgrowth of any tumor escape variants, we prepared the final vaccines as multitarget NeoAG vaccines (figure $2 \mathrm{D}$ ). The vaccine with the short peptides was termed $Q \beta(1668)-\mathrm{NeoAG}_{\mathrm{S}}$ and the vaccine with the long peptides was termed $\mathrm{Q} \beta(1668)-\mathrm{NeoAG}_{\mathrm{L}}$, each containing one of the neoantigenic peptides with the mutations identified in Vrk3 (E391K), Thap3 (H75Y) or Sult2b1 (H299N). The mutation in Vrk3 (E391K) was retrieved in two different MHC-I neoepitopes. The sequences and treatment doses are listed in table 2.

\section{Superior in vivo efficacy by the long peptide vaccine as opposed to the short peptide vaccine}

We compared the in vivo anti-tumor efficacy of the short and long peptide vaccines. To this end, the aggressive $4 \mathrm{~T} 1$ mammary carcinoma cell line was inoculated s.c. in Balb/c 
A

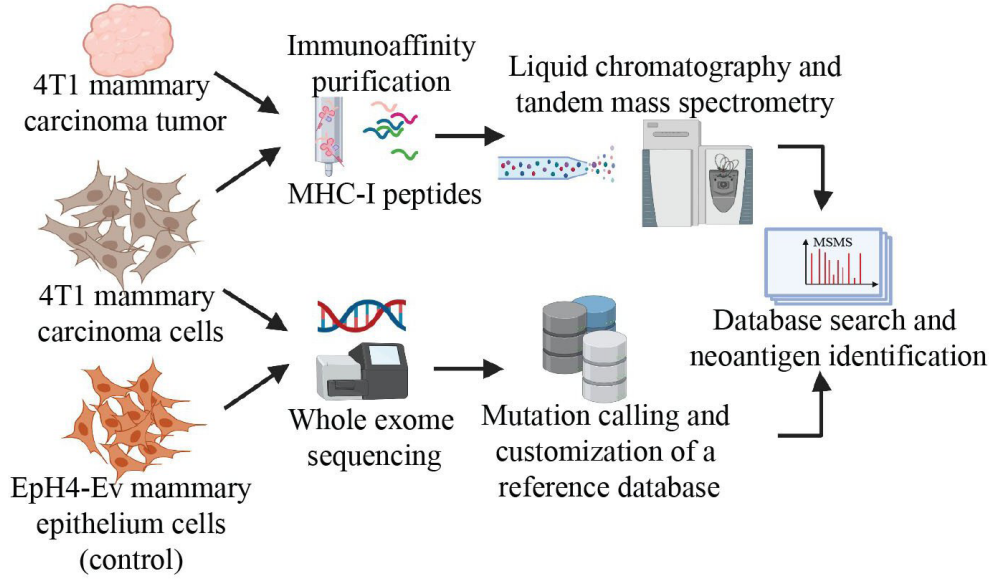

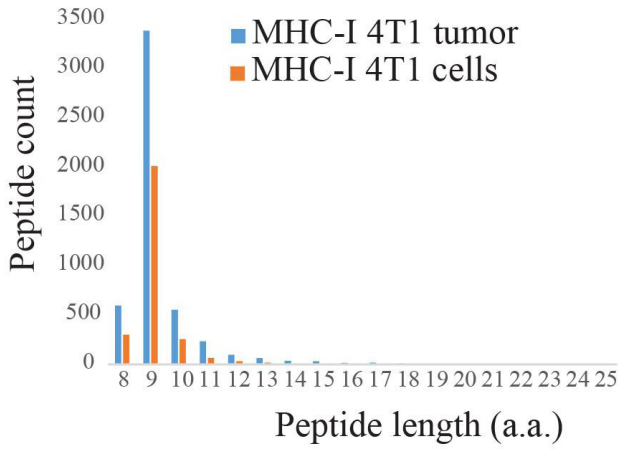

D 9 mer MHC-I peptides - 4T1 tumor
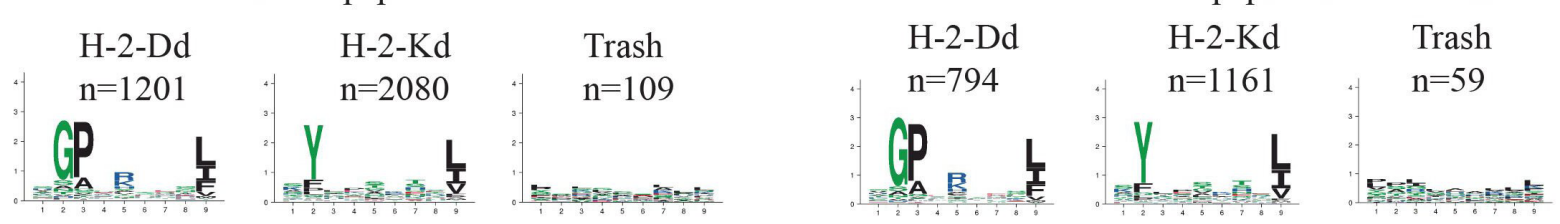

F

E

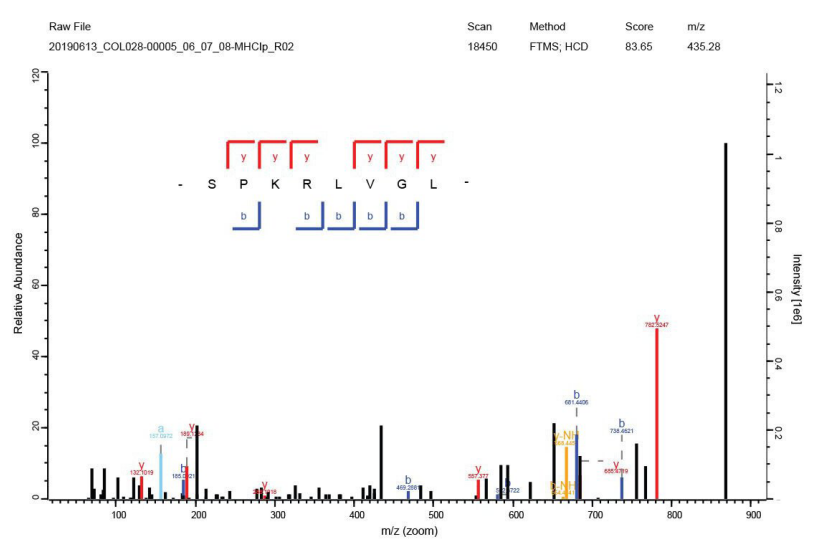

G

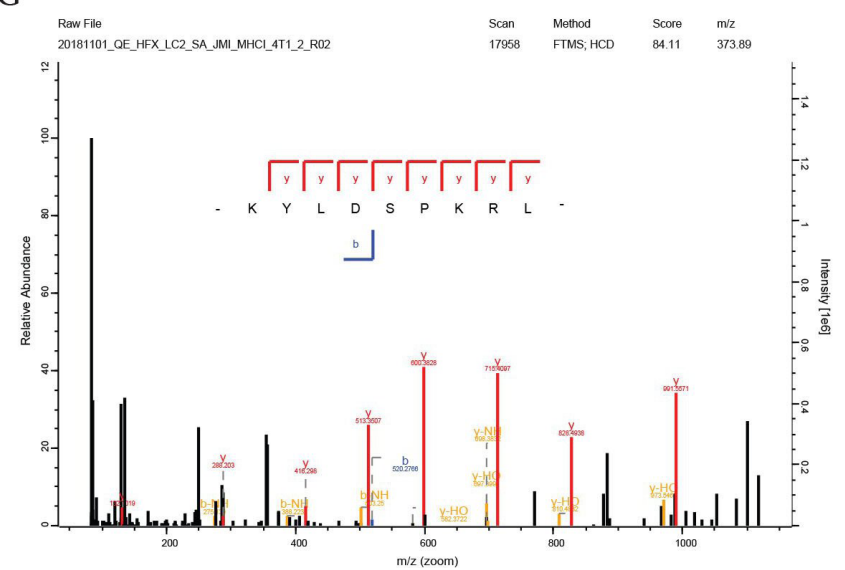

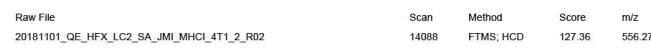

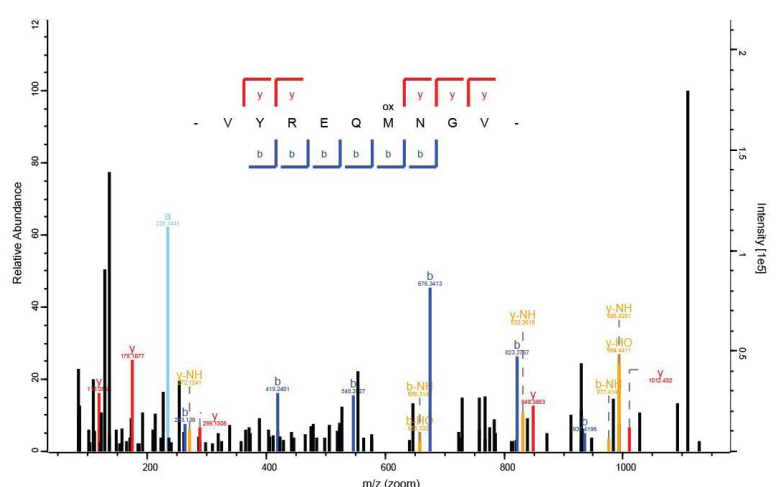

$\mathrm{H}$

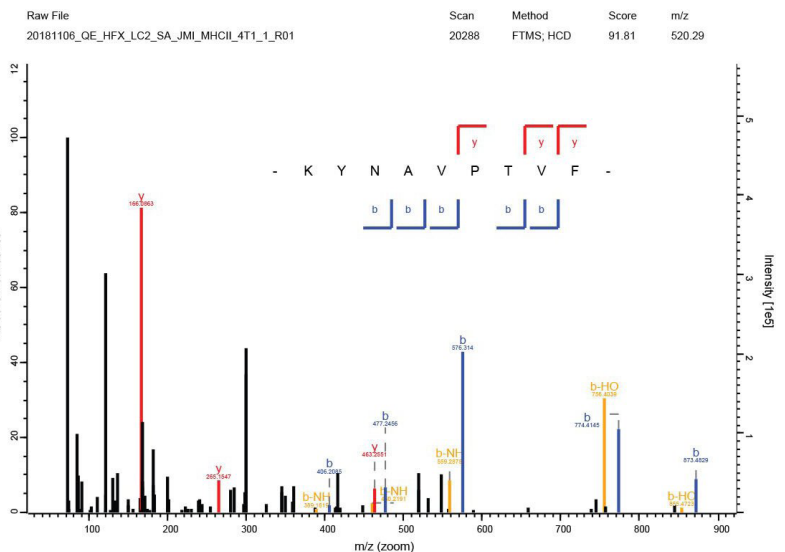

Figure 1 NeoAG identification. (A) Schematic representation of our approach for NeoAG identification. (B) Length distribution of MHC-I peptides identified by immunopeptidomics from 4T1 cells grown in vivo or in vitro. (C) Clustering of 9-mer MHC-I peptides identified in $4 \mathrm{~T} 1$ cells grown in vivo and (D) in 4T1 cells grown in vitro. (E)-(H) Annotated MSMS spectra of the NeoAG identified by MaxQuant in 4T1 cells. MSMS spectra were exported from the MaxQuant viewer. NeoAG, neoantigens. 
A

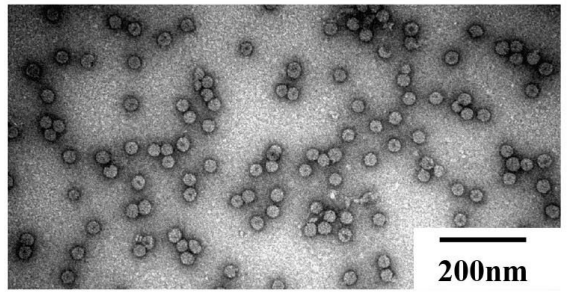

B

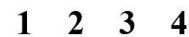

C

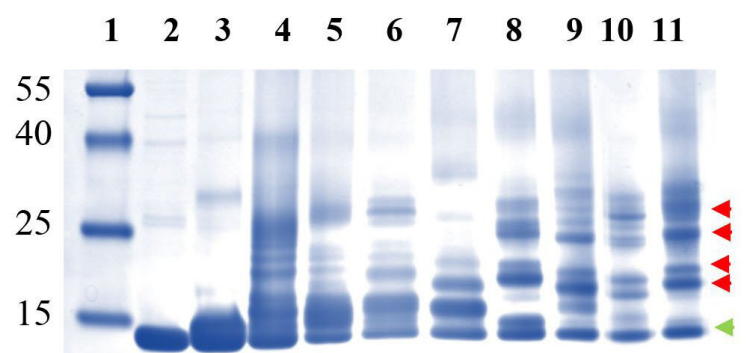

D

\section{$Q \beta(1668)-$ NeoAG $_{\mathrm{S}}$}
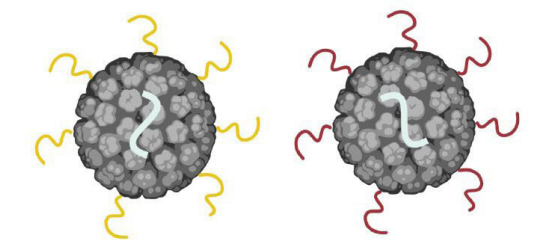

$Q \beta(1668)-N e 0 A G_{S-1} Q \beta(1668)-N e o A G_{S-2}$
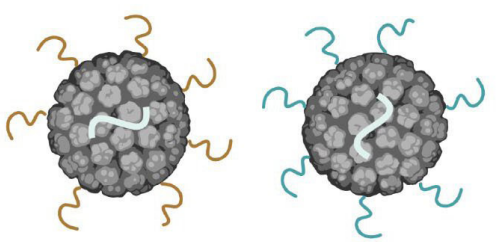

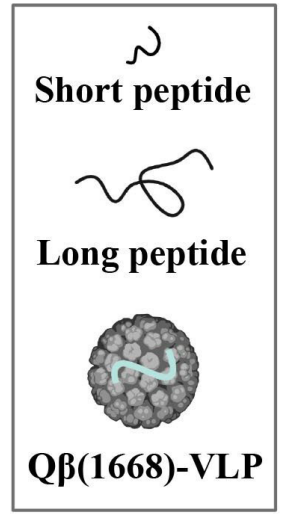

$Q \beta(1668)-N^{-N e o A G} G_{S-3} \quad Q \beta(1668)-N^{2} 0 A G_{S-4}$

$Q \beta(1668)-N^{20} A G_{L}$

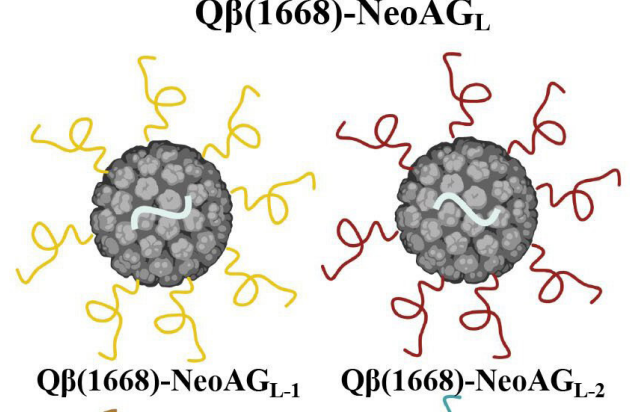

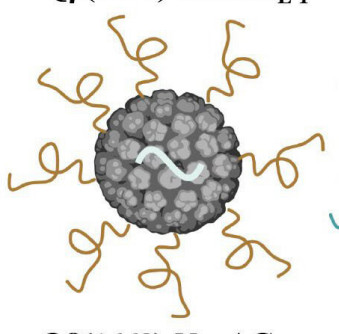

Qß(1668)-NeoAG ${ }_{L-3}$

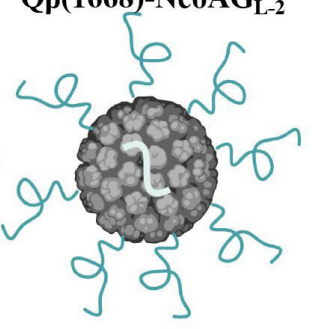

$\mathrm{Q} \beta(1668)-\mathrm{NeoAG}_{\mathrm{L}-4}$

Figure 2 Efficient coupling of synthetic NeoAG peptides by Cu-free click chemistry to VLPs. (A) Electron microscopy imaging of the QB(ssRNA)-VLPs used for vaccine development. (B) (Top) 1\% agarose gel stained with SYBR Safe dye, lane 1: DNA marker, lane 2: $10 \mu \mathrm{g}$ of QB(ssRNA)-VLPs, lane 3: $10 \mu \mathrm{g}$ of QB(empty)-VLPs digested with RNase A and lane 4: $10 \mu \mathrm{g}$ of $\mathrm{Q} \beta(1668)$-VLPs re-packaged with B-type CpGs. (Bottom) Coomassie Blue staining of the agarose gel to confirm integrity of the VLPs, similar lanes as indicated on top. (C) SDS-PAGE stained with Coomassie Blue, lane 1: protein ladder, lane 2: $6 \mu \mathrm{g}$ of

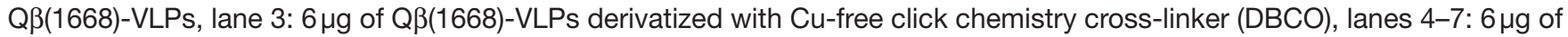
Qß(1668)-VLPs derivatized with Cu-free click chemistry cross-linker (DBCO) and coupled to NeoAG1 or NeoAG2 or NeoAG3 or NeoAG4 (15-16a.a. short peptides), lanes 8-11: $6 \mu \mathrm{g}$ of QB(1668)-VLPs derivatized with Cu-free click chemistry cross-linker (DBCO) and coupled to NeoAG1 or NeoAG2 or NeoAG3 or NeoAG4 (32 a.a. long peptides). The green arrow points to QB(1668)VLP monomers and red arrows point to a peptide bound to $Q \beta$ monomer. (D) Cartoon illustrating the multitarget vaccines: $\mathrm{Q} \beta(1668)-\mathrm{NeoAG}_{\mathrm{S}}$ (left) and $\mathrm{Q} \beta(1668)-N e o A G_{\mathrm{L}}$ (right). a.a., amino acids; NeoAG, neoantigens; ssRNA, single-stranded RNA; VLPs, virus-like particles.

mice as described in the "cell lines and mice section". On day 3 , day 7 and day 13 , s.c. vaccinations were done with $\mathrm{Q} \beta(1668)-\mathrm{NeoAG}_{\mathrm{S}}, \mathrm{Q} \beta(1668)-\mathrm{NeoAG}_{\mathrm{L}}$ or $\mathrm{Q} \beta(1668)$ as control without peptides (figure 3A). Vaccination with the $Q \beta(1668)-\mathrm{NeoAG}_{\mathrm{s}}$ significantly $(\mathrm{p}=0.0091)$ hindered tumor progression as compared with the $\mathrm{Q} \beta(1668)$ control. Interestingly, the long peptide vaccine $Q \beta(1668)-\mathrm{NeoAG}_{\mathrm{L}}$ showed better enhanced anti-tumor efficacy $(\mathrm{p}<0.0001)$ (figure 3B-D). We also included a saline (PBS) control and no statistical difference was detected between mice that received saline or $Q \beta(1668)$ control (online supplemental figure 3). It is well known that infiltration of $\mathrm{CD} 8^{+} \mathrm{T}$ cells into the tumor correlates with better prognosis, which serves as an essential piece of evidence for effective immune responses in melanoma ${ }^{3637}$ as well as breast cancer. ${ }^{38}$ Furthermore, it has been suggested that the majority of immunogenic NeoAG in personalized cancer vaccines activate $\mathrm{CD} 4^{+} \mathrm{T}$ cells. ${ }^{39}$ Accordingly, we determined the density of $\mathrm{CD} 8^{+}$and $\mathrm{CD} 4^{+} \mathrm{T}$ cells in each tumor. No significant differences were found for $\mathrm{CD} 8^{+}$ $(\mathrm{p}=0.9759)$ or $\mathrm{CD}_{4}^{+}(\mathrm{p}=0.847)$ T cell infiltration between the control group and the group treated with the short peptide 
A

4T1

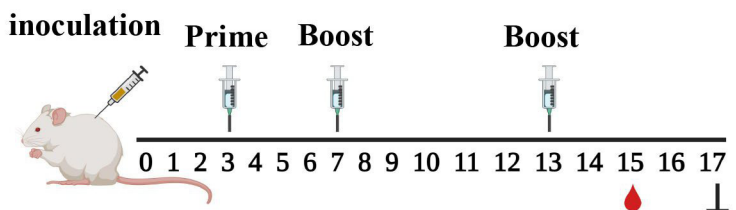

B

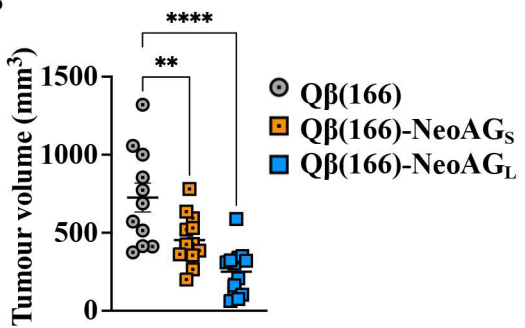

C

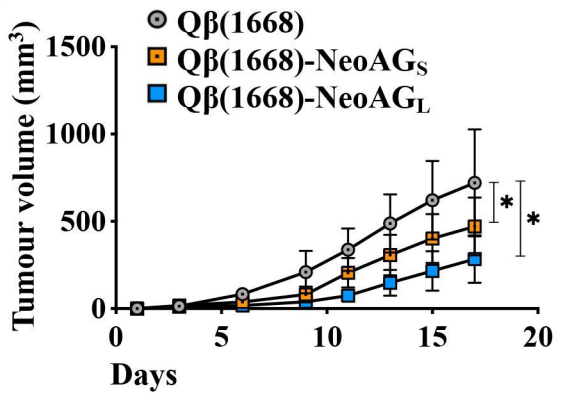

E

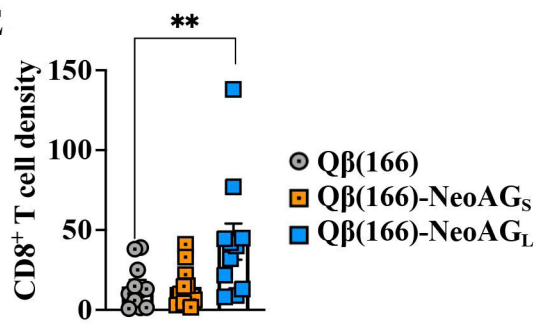

G

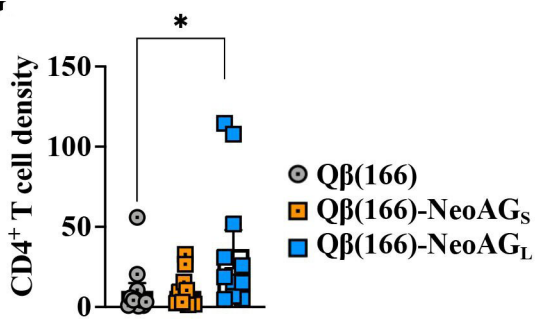

I

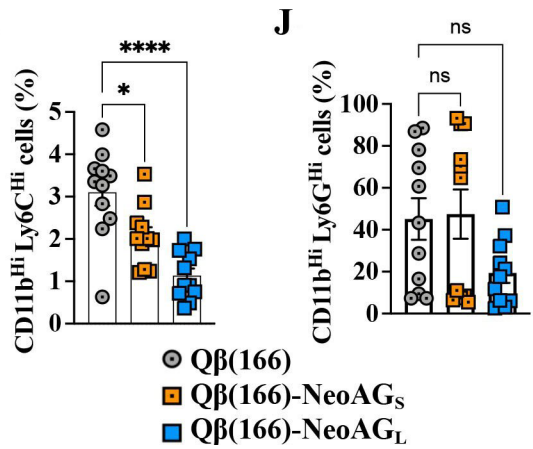

D

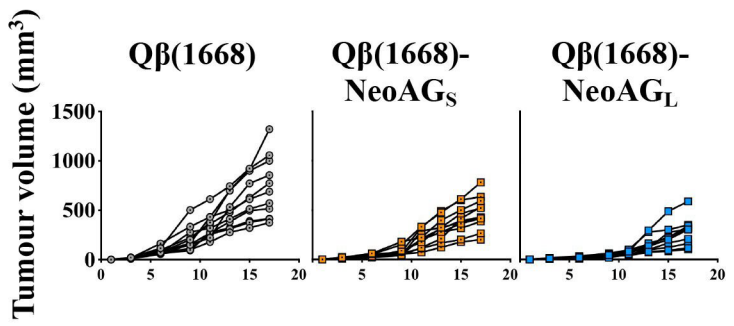

Days

F

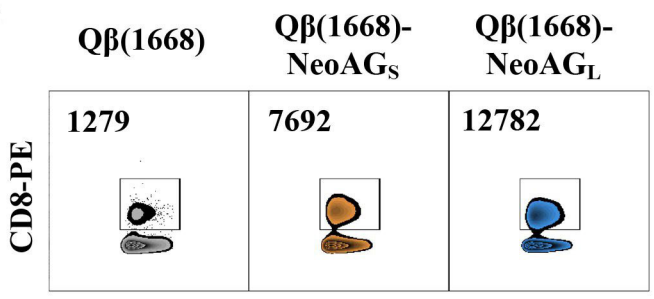

FSC-A

H $\quad Q \beta(1668) \quad Q \beta(1668)-\quad Q \beta(1668)-$

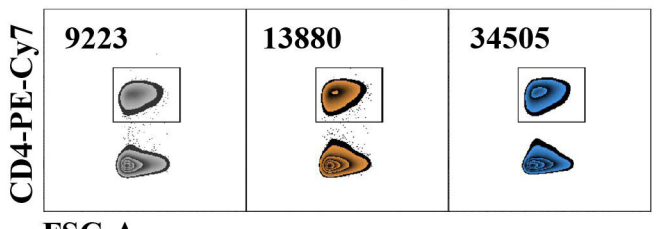

FSC-A

Figure 3 Superior in vivo efficacy by the long as opposed to the short peptide vaccine. (A) Treatment regimen using a prime and two boost vaccinations as summarized in table 2. (B) Tumor volume in $\mathrm{mm}^{3}$ measured on day 17 post $4 \mathrm{~T} 1$ inoculation. Each dot represents an individual tumor. (C) Tumor growth curves of the treated groups. (D) Individual tumor growth curves of the treated groups. (E) and (G) Density of $\mathrm{CD}^{+}$or $\mathrm{CD} 4^{+} \mathrm{T}$ cells in tumors as determined by flow cytometry. The densities were determined by dividing the total number of $\mathrm{CD}^{+}$or $\mathrm{CD} 4^{+} \mathrm{T}$ cells in each tumor by the tumor volume in $\mathrm{mm}^{3}$, pre-gated on TILs. $(\mathrm{F})$ and $(\mathrm{H})$ Representative FACS plots showing the percentage of $\mathrm{CD}^{+}$or $\mathrm{CD}^{+}$or T cells in tumors, pre-gated on TILs. (I) and (J) Percentage of $\mathrm{CD} 11 \mathrm{~b}^{\mathrm{Hi}} \mathrm{Ly} 6 \mathrm{C}^{\mathrm{Hi}}$ or $\mathrm{CD} 11 \mathrm{~b}^{\mathrm{Hi}} \mathrm{Ly}_{6 \mathrm{G}^{\mathrm{Hi}}}$ cells in peripheral blood 15 days post $4 \mathrm{~T} 1$ inoculation. (K) A representative FACS plot showing the percentage of $\mathrm{CD} 11 \mathrm{~b}^{\mathrm{Hi}} \mathrm{Ly} 6 \mathrm{C}^{\mathrm{Hi}}$ in peripheral blood 15 days post $4 \mathrm{~T} 1$ inoculation, pre-gated on monocytes. Statistical analysis (mean \pm SEM) by one-way ANOVA (B), AUC and Student's t-test (C) and Bonferroni test (E, G, I and $\mathrm{J}$. ( $(n=11)$, one representative of two similar experiments is shown. AUC, area under curve; NeoAG, neoantigens; TILs, tumor infiltrating lymphocytes. 
vaccine. Yet, a considerably increased $\mathrm{CD} 8^{+} \mathrm{T}$ cell infiltration was observed after long peptide vaccination (figure 3E,F). The infiltration of $\mathrm{CD} 4^{+} \mathrm{T}$ cell was also increased after long peptide vaccination (figure $3 \mathrm{G}, \mathrm{H}$ ). To study the systemic effects of the vaccinations, we characterized $\mathrm{CD} 8^{+}$and $\mathrm{CD} 4^{+}$ $\mathrm{T}$ cells in peripheral blood 15 days post $4 \mathrm{~T} 1$ inoculation. We found no significant differences between the groups (data not shown). We also assessed MDSCs characterized by $\mathrm{CD} 11 b^{\mathrm{Hi}} \mathrm{Ly}_{6 \mathrm{C}} \mathrm{Hi}^{\mathrm{Hi}}$ or $\mathrm{CD} 11 b^{\mathrm{Hi}} \mathrm{Ly}_{6 \mathrm{G}}{ }^{\mathrm{Hi}}$ (figure $3 \mathrm{I}-\mathrm{K}$ ). Interestingly, the percentage of $\mathrm{CD} 11 \mathrm{~b}^{\mathrm{Hi}} \mathrm{Ly} 6 \mathrm{C}^{\mathrm{Hi}}$ was significantly decreased in the group treated with $Q \beta(1668)-N_{e} A G_{S}$ when compared with the control group $(p=0.026)$. The long peptide vaccine $Q \beta(1668)-N_{e o A G}$ was even more efficient in diminishing this population in comparison to the control group $(\mathrm{p}=0.0002)$.

\section{In the tumor microenvironment, the long peptide vaccine reduced MDSCs and increased IFN- $\gamma$ and TNF- $\alpha$ production by T cells}

Based on its superiority, we focused on the long peptide vaccine $\mathrm{Q} \beta(1668)-\mathrm{NeoAG}_{\mathrm{L}}$. To explore whether the induced immune response is mediated by a single NeoAG or the multiple ones, mice were vaccinated with $Q \beta(1668)$ $\mathrm{NeoAG}_{\mathrm{L}}-1$ or $\mathrm{Q} \beta(1668)-\mathrm{NeoAG}_{\mathrm{L}}-2$ or $\mathrm{Q} \beta(1668)-\mathrm{NeoAG}_{\mathrm{L}}-3$ or $Q \beta(1668)-\mathrm{NeoAG}_{\mathrm{L}}-4$ separately or with the multitarget vaccine $\mathrm{Q} \beta(1668)-\mathrm{NeoAG}_{\mathrm{L}}$. Splenocytes of vaccinated mice were collected and stimulated with each corresponding NeoAG peptide, or with a combination of the four neoantigenic peptides for the group vaccinated with the multitarget vaccine. The results showed that vaccination with the multitarget vaccine induced significantly increased TNF- $\alpha$ production in $\mathrm{CD}^{+}$and $\mathrm{CD} 4^{+} \mathrm{T}$ cells in comparison to mice vaccinated with a single NeoAG (figure 4A,B). Significantly increased production of IFN- $\gamma$ in $\mathrm{CD}^{+} \mathrm{T}$ cells but not in $\mathrm{CD} 4^{+} \mathrm{T}$ cells could also be detected in the group vaccinated with the multitarget vaccine (figure $4 \mathrm{C}, \mathrm{D}$ ).

In order to characterize the intratumoral immune response induced by vaccination, we compared tumors from control mice with those after vaccination with the long multitarget peptide vaccine $\mathrm{Q} \beta(1668)-\mathrm{NeoAG}_{\mathrm{L}}$. The results confirmed that long peptide vaccination can significantly hinder $4 \mathrm{~T} 1$ tumor growth $(\mathrm{p}=0.0022)$ when compared with the control group treated with $Q \beta(1668)$ (figure $4 \mathrm{E}$ ). $\mathrm{T}$ cell density was assessed in each tumor by flow cytometry. We found significantly enhanced intratumoral infiltration of $\mathrm{CD}^{+}$and $\mathrm{CD} 4^{+} \mathrm{T}$ cells $(\mathrm{p}=0.0005$ and $\mathrm{p}=0.0035$, respectively) (figure $4 \mathrm{~F}, \mathrm{G}$ ), inversely correlating with tumor volume $(\mathrm{p}=0.0089$ and $\mathrm{p}=0.0079$, respectively) (figure $4 \mathrm{H}, \mathrm{I})$. Furthermore, we determined the production of IFN- $\gamma$ and TNF- $\alpha$ by $\mathrm{CD} 8^{+}$and $\mathrm{CD} 4^{+}$ $\mathrm{T}$ cells after stimulation of $\mathrm{T}$ cells with a cocktail of the long peptides. Production of IFN- $\gamma$ by specific $\mathrm{CD}^{+} \mathrm{T}$ cells was significantly increased $(\mathrm{p}=0.0022)$ (figure $4 \mathrm{~J})$. Despite a trend, the difference for TNF- $\alpha$ production was not significant, likely related to the high heterogeneity (figure $4 \mathrm{~K}$ ). When assessing specific $\mathrm{CD}^{+} \mathrm{T}$ cells producing both cytokines, a significant increase was found after long peptide vaccination as compared with control mice $(\mathrm{p}=0.0022)$ (figure $4 \mathrm{~L}, \mathrm{M})$. The results also showed significant increase of IFN- $\gamma$ or TNF- $\alpha$ production in specific $\mathrm{CD}^{+} \mathrm{T}$ cells $(\mathrm{p}=0.0022$ and $\mathrm{p}=0.0303$, respectively) (figure $4 \mathrm{~N}, \mathrm{O}$ ) after long peptide vaccination compared with controls. This was also the case for the specific polyfunctional $\mathrm{CD} 4^{+} \mathrm{T}$ cells that simultaneously produced both cytokines $(\mathrm{p}=0.0022$ ) (figure $4 \mathrm{P}, \mathrm{Q})$. Finally, we also studied the effect of vaccination on intratumoral monocytic and granulocytic myeloid cells. Interestingly, both intratumoral $\mathrm{CD} 11 \mathrm{~b}^{\mathrm{Hi}} \mathrm{Ly}_{6} \mathrm{C}^{\mathrm{Hi}}$ and the $\mathrm{CD} 11 \mathrm{~b}^{\mathrm{Hi}} \mathrm{Ly}_{6 \mathrm{G}}^{\mathrm{Hi}}$ cells were significantly decreased after long peptide vaccination (figure 4R,S) indicating a decrease in myeloid-suppressor cells

\section{Long peptide vaccination decreases post-surgical tumor recurrence and lung metastases, and prolongs survival}

The observed efficacy of vaccination with $\mathrm{Q} \beta(1668)$ $\mathrm{NeoAG}_{\mathrm{L}}$ in vivo promoted us to address whether the vaccine may be useful in a clinically relevant perspective, namely, to prevent tumor progression after surgical resection of the primary tumor. To this end, 1 million $4 \mathrm{~T} 1$ cells were inoculated in the left flank of the mice. Treatment with $Q \beta(1668)$ as a control or with the multitarget vaccine $Q \beta(1668)-N_{e o A G}$ was initiated 3 days later. Mice received 3 doses over 13 days and primary tumors were surgically resected on day 14 , followed by 2 treatment doses weekly (figure $5 \mathrm{~A})$. $\mathrm{Q} \beta(1668)-\mathrm{NeoAG}_{\mathrm{L}}$ hindered $4 \mathrm{~T} 1$ primary tumor progression as shown in figure $5 \mathrm{~B}, \mathrm{C}$ confirming our findings. By IHC, we investigated $\mathrm{CD} 4^{+}$ and $\mathrm{CD}^{+} \mathrm{T}$ cell infiltration into the primary tumors (figure 5D). We found a significant increase $(\mathrm{p}=0.0229)$ in the numbers of peritumoral $\mathrm{CD} 4^{+} \mathrm{T}$ cells in the group vaccinated with $\mathrm{Q} \beta(1668)-\mathrm{NeoAG}_{\mathrm{L}}$ in comparison to the control group (figure 5E-top). The numbers of intratumoral $\mathrm{CD} 4^{+} \mathrm{T}$ cells were heterogeneous and showed a trend but no significant increase in the group vaccinated with $\mathrm{Q} \beta(1668)-\mathrm{NeoAG}_{\mathrm{L}}$ (figure $5 \mathrm{E}$, bottom, and online supplemental figure 6 ). After surgical resection of primary tumors, the weight of mice in the control group remained stable for 10 days (until day 24 of primary tumor inoculation) but started to drop sharply thereafter when all the mice of the control group had to be sacrificed at days 39-40 after primary tumor inoculation. The mice vaccinated with the multitarget $Q \beta(1668)-N_{e o} G_{L}$ showed much less weight loss and remained stable after day 40 (for the surviving mice) (figure 5F). However, the weight loss in some of the immunized mice required that $20 \%$ of the mice had to be euthanised on day 42 and $20 \%$ on day 48 , whereas the remaining $60 \%$ of mice continued completely healthy and had stable weight until the end of the experiment on day 66 (figure 5G). We measured the weight of the lungs of euthanised mice to quantify lung metastases. The results reflect extensive 4T1 lung metastases in the control group, whereas long peptide vaccination resulted in significantly less lung metastases in the mice that were euthanised due to weight loss, and no lung metastases in the remaining $60 \%$ of the mice at the end of 


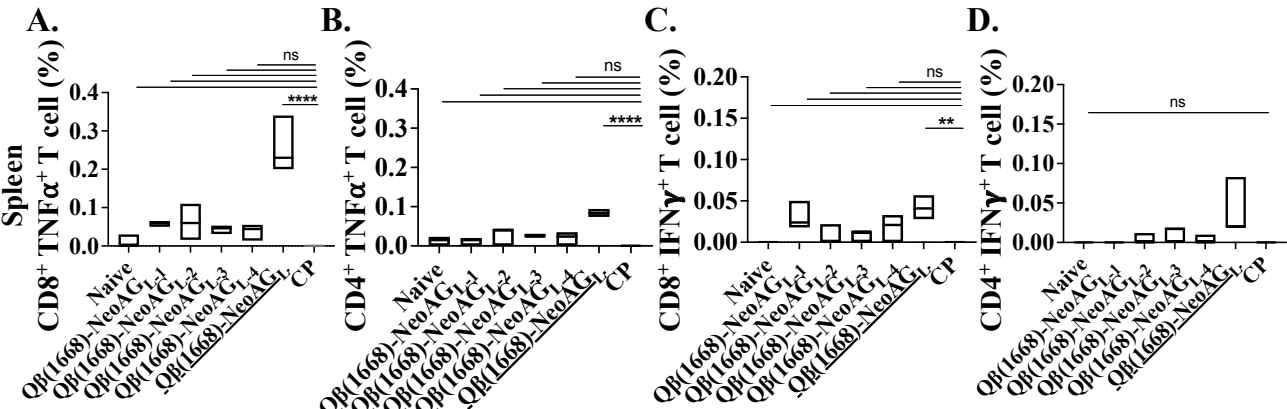

E.

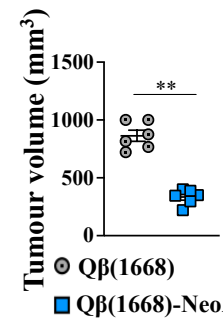

J.

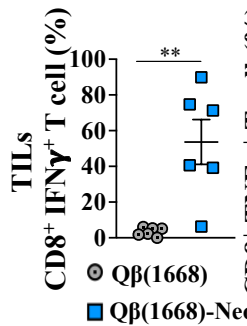

F.

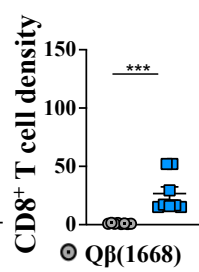

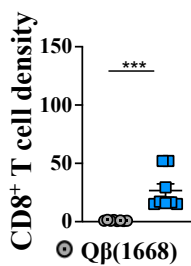

H.
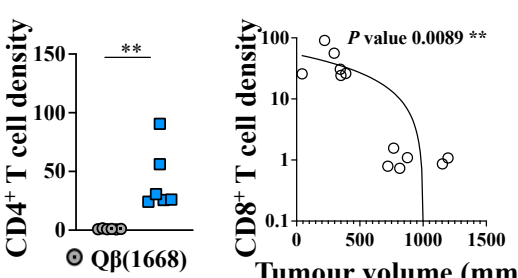

I.

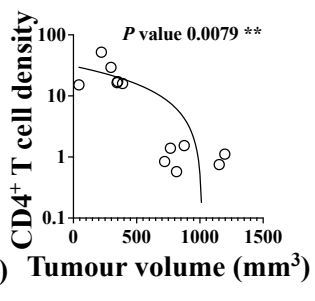

K.

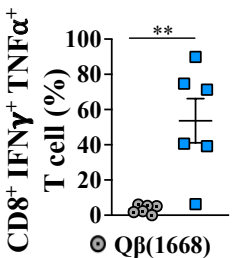
Tumour volume $\left(\mathrm{mm}^{3}\right)$ Tumour volume $\left(\mathrm{mm}^{3}\right)$ $\mathbf{T G}_{\mathrm{L}}$

M.

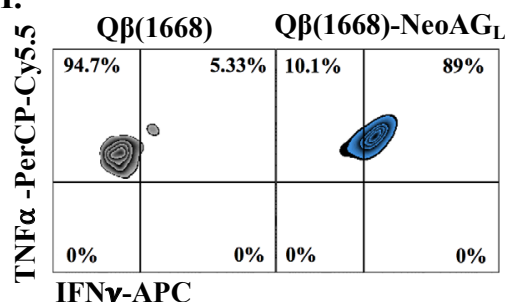

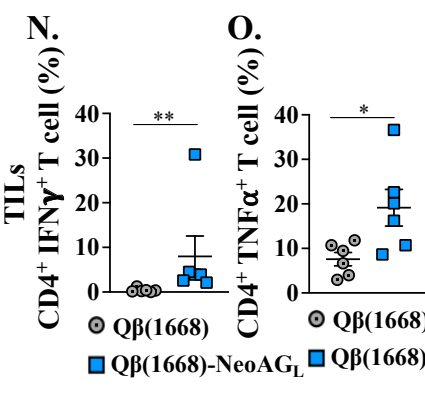

R.

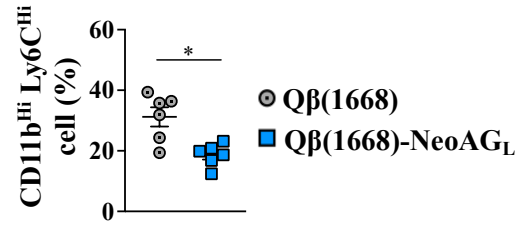

P.

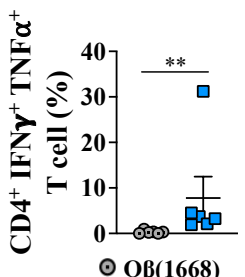

Q.

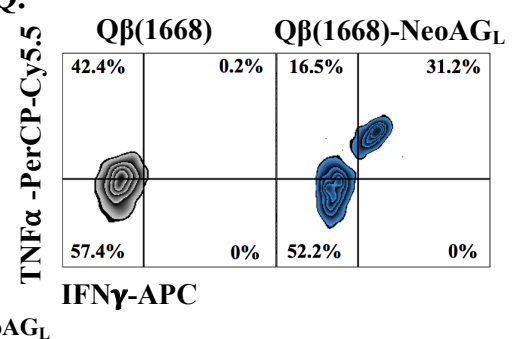

Figure 4 In the tumor microenvironment, the long peptide vaccine reduced MDSCs and increased IFN- $\gamma$ and TNF- $\alpha$ production by T cells. (A) and (B) Percentage of $\mathrm{CD} 8^{+} \mathrm{TNF}-\alpha^{+}$or $\mathrm{CD} 4^{+} \mathrm{TNF}-\alpha^{+}$cells in splenocytes from mice treated with vaccines with single long peptide 1,2,3 or 4, or all 4 long peptides (multitarget $Q \beta(1668)-N e o A G_{L}$ vaccine, underlined). (C) and (D) Percentage of $\mathrm{CD}^{+}$IFN- $\gamma^{+}$or $\mathrm{CD}^{+}$IFN- $\gamma^{+} \mathrm{T}$ cells in splenocytes from the same mice. Naive and control peptide (CP) were used. (E) Tumor volume in $\mathrm{mm}^{3}$ measured on day 17 post $4 \mathrm{~T} 1$ inoculation of control mice treated with $\mathrm{Q} \beta(1668)$ or mice vaccinated with $Q \beta(1668)-N e o A G$. Each dot represents an individual tumor. $(F)$ and $(G) C D 8^{+}$or $C D 4^{+} T$ cell density in tumors as determined by flow cytometry and dividing the total number of $\mathrm{CD} 4^{+}$or $\mathrm{CD} 8^{+} \mathrm{T}$ cell in each tumor by the tumor volume in $\mathrm{mm}^{3}$. $(\mathrm{H})$ and $(\mathrm{I})$ Correlations between $\mathrm{CD}^{+}$or $\mathrm{CD}^{+} \mathrm{T}$ cells density in each tumor and its corresponding tumor volume in $\mathrm{mm}^{3}$. (J)-(L) Percentage of $\mathrm{CD}^{+}$IFN- $\gamma^{+}, \mathrm{CD}^{+} \mathrm{TNF}-\alpha^{+}$and dual IFN- $\gamma^{+}$, TNF- $\alpha^{+} \mathrm{CD}^{+}$T cell in tumors. (N)-(P) Percentage of CD4 $4^{+}$IFN- $\gamma^{+}$, CD4 ${ }^{+}$TNF- $\alpha^{+}$and dual IFN- $\gamma^{+}$, TNF- $\alpha^{+} \mathrm{CD}^{+}$T cell in tumors. (M) and (Q) Representative FACS plots showing the percentage of dual IFN- $\gamma^{+}$, TNF- $\alpha^{+} \mathrm{CD}^{+}$or $\mathrm{CD} 4^{+} \mathrm{T}$ cell in tumors. (R) and (S) Percentage of $\mathrm{CD} 11 \mathrm{~b}^{\mathrm{Hi}} \mathrm{Ly}_{6 \mathrm{C}^{\mathrm{Hi}}}$ or CD11b $\mathrm{b}^{\mathrm{Hi}} \mathrm{Ly}_{6 \mathrm{G}}{ }^{\mathrm{Hi}}$ cells in tumors. Statistical analysis (mean \pm SEM) by Student's t-test. $(n=6)$, one representative of 2 similar experiments is shown. IFN, interferon; MDSCs, myeloid-derived suppressor cells; NeoAG, neoantigen. 
A

4T1

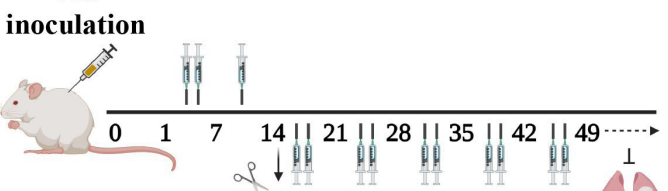

Primary tumour resection
Endpoint Lung metastasis

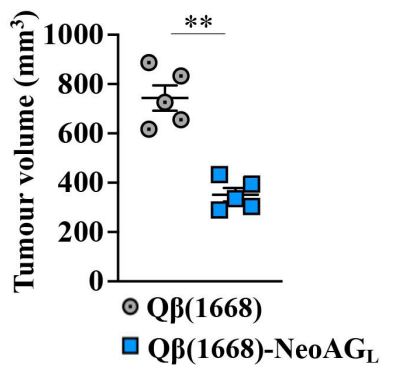

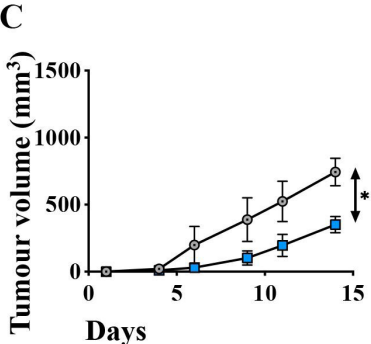

F

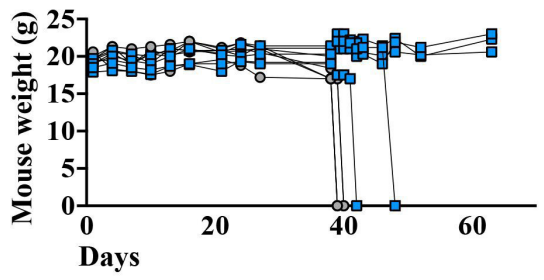

$\mathbf{H}$

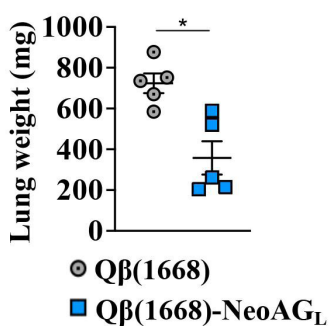

D

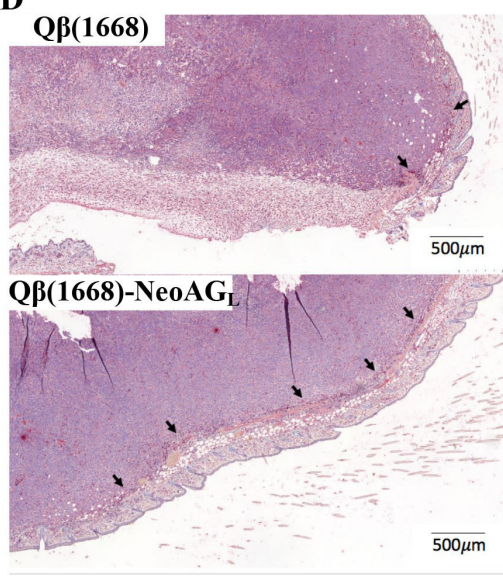

E

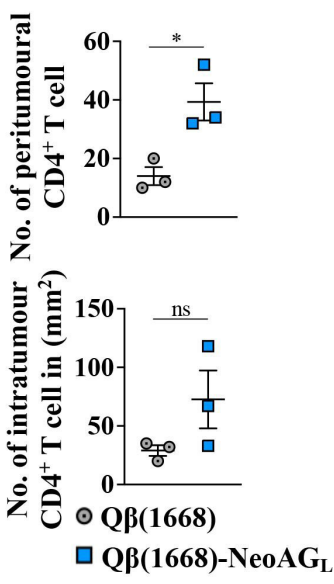

Figure 5 Long peptide vaccination decreases post-surgical tumor recurrence and lung metastases, and prolongs survival. (A) Mice were inoculated with $1 \times 10^{6} 4 \mathrm{~T} 1$ cells on day 0 and vaccinated 3 times over 13 days. Primary tumors were surgically resected on day 14 under isoflurane anesthesia, followed by 2 vaccinations weekly until the end of the experiment. Mice were

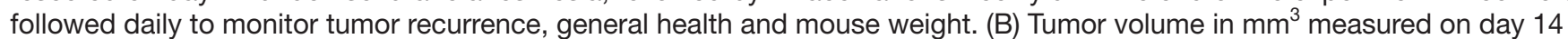
post 4T1 inoculation of control mice treated with $Q \beta(1668)$ or mice vaccinated with $Q \beta(1668)-N e o A G_{L}$. Each dot represents an individual tumor. (C) Tumor growth curves of the treated groups. (D) Representative immunohistochemistry (IHC) staining of $\mathrm{CD}^{+} \mathrm{T}$ cell in tumors of mice treated with $\mathrm{Q} \beta(1668)$ as control or $\mathrm{Q} \beta(1668)-\mathrm{NeoA} \mathrm{G}_{\mathrm{L}}$. Arrows point to peritumoral CD4 ${ }^{+} \mathrm{T}$ cell $(n=3)$. (E) Numbers of peritumoral (top) and intratumoral $/ \mathrm{mm}^{2}$ (bottom) CD4 ${ }^{+} \mathrm{T}$ cell, respectively. (F) Mice weight $(\mathrm{g})$ during the experiment. (G) Survival of mice in both groups; mice were euthanized when loosing 10\%-15\% of their original weight. (H) Lung weight (mg); mice were euthanized when loosing $10 \%-15 \%$ of their original weight and lungs were collected. (I) Representative photos of lungs from euthanized mice (control and $Q \beta(1668)-N e o A_{L}$ ); arrows point to lung metastases. For the group treated with $Q \beta(1668)-N e o A G_{L}$, two lung samples are from the mice which were euthanized due to weight loss and one lung from a mouse that remained healthy and without metastases until the end of the experiment. $(\mathrm{J})$ Correlation between primary tumor volume in $\mathrm{mm}^{3}$ and end-point lung weight $(\mathrm{mg})$. Statistical analysis (mean \pm SEM) by Student's t-test, AUC (C), log-rank test $(\mathrm{H})$ and Ozone correlations $(\mathrm{K})$. ( $(\mathrm{n}=5)$, one representative of 2 similar experiments is shown. IHC, AUC, area under curve; IHC, immunohistochemistry. 
the experiment $(\mathrm{p}=0.0159) \quad$ (figure $5 \mathrm{H}, \mathrm{I})$. Analyzing the volume of the primary tumor and lung weight revealed a significant correlation $(\mathrm{p}=0.0268)$ (figure $5 \mathrm{~J})$. To assess the role of $\mathrm{CD}^{+} \mathrm{T}$ cells in the effects of vaccination with $\mathrm{Q} \beta(1668)-\mathrm{NeoAG}_{\mathrm{L}}$, we depleted $\mathrm{CD}^{+} \mathrm{T}$ cells. Three groups of mice were analyzed: a control group treated without tumor antigens (ie, $\mathrm{Q} \beta(1668)$ alone), a group which received 3 doses of the multitarget $\mathrm{Q} \beta(1668)$ $\mathrm{NeoAG}_{\mathrm{L}}$ vaccine over 14 days, and a third group which received the same vaccination plus anti-CD8 monoclonal antibody. Efficient CD8 ${ }^{+} \mathrm{T}$ cells depletion of $\sim 99 \%$ was confirmed in the third group by flow cytometry (online supplemental figure 5A). The effect of vaccination with $Q \beta(1668)-N_{e o A G}$ was significantly abrogated in the $\mathrm{CD}^{+} \mathrm{T}$ cell-depleted mice compared with non-depleted ones $(p<0.0001) \quad$ (online supplemental figure $5 B$ ). To further study the effect of $\mathrm{CD} 8^{+} \mathrm{T}$ cells depletion in the different groups, primary tumors were resected on day 14 and mice were followed for $\sim 50$ days without any additional vaccination. Our results showed reduced survival in the control group and the $\mathrm{CD} 8^{+} \mathrm{T}$ cell-depleted mice when compared with the vaccinated group ( $p=0.0024$ and $\mathrm{p}=0.0008$, respectively) (online supplemental figure $5 \mathrm{C}$ ). Therefore, the beneficial anti-tumor effect of vaccination with $\mathrm{Q} \beta(1668)-\mathrm{NeoAG}_{\mathrm{L}}$ depends on $\mathrm{CD}^{+} \mathrm{T}$ cells.

\section{DISCUSSION}

In this study, we developed a universal approach for a personalized cancer vaccine. We found efficient tumor control through activation and functional competence of both $\mathrm{CD}^{+}$and $\mathrm{CD} 4^{+} \mathrm{T}$ cells, associated with reduction of suppressive myeloid cells both in circulation and within tumors. The vaccine was based on the successful identification of neoantigenic peptides using mass spectrometrybased immunopeptidomics combined with WES and wet-bench validation. The advantage of this experimental approach relies on the fact that it only identifies peptides that are indeed naturally presented by MHC molecules on the surface of tumor cells, thus avoiding the frequent epitope prediction failures by other techniques that do not rely on the physical identification of peptides. Indeed, our approach has been shown to enrich for NeoAG that are capable of controlling tumors in mice in vivo. ${ }^{40}$ To avoid possible outgrowth of tumor escape variants, we produced a multitarget vaccine with four neoantigenic peptides.

We synthesized short peptides corresponding to $\mathrm{CD} 8^{+}$ $\mathrm{T}$ cell epitopes or long peptides, including both $\mathrm{CD} 8^{+}$ and $\mathrm{CD}^{+} \mathrm{T}$ cell epitopes. Using the bio-orthogonal $\mathrm{Cu}$-free click chemistry, peptides were coupled to VLPs consisting of recombinant bacteriophage $\mathrm{Q} \beta$ protein and loaded with the B-type CpG 1668. The applied chemical coupling has several advantages as compared with other methods such as using SMPH linker. ${ }^{21}$ SMPH may react with internal cysteine within epitopes, causing their inactivation. Additionally, non-reacted SMPH on VLPs can be toxic and may complicate the Good manufacturing practice (GMP) process, in particular at bedside. Cu-free click chemistry is a non-toxic method, as the azide group added to the C-terminal end of the synthesized peptides is metabolically stable and lacks any reactivity with other biological functionalities in human cells. Cu-free chemistry has shown high selectivity in several studies, for example, for imaging, labeling and tracking cells in vivo. ${ }^{41}{ }^{42}$ A key advantage of this method is that it can be applied at the bedside, enabling easy and rapid production of personalized vaccines for each patient directly where and when needed.

The short peptide vaccine significantly hindered tumor progression $(\mathrm{p}=0.0091)$ when compared with the antigen negative control vaccine. However, this vaccine did not enhance $\mathrm{CD}^{+}$nor $\mathrm{CD}^{+} \mathrm{T}$ cell infiltration into the tumors. Nevertheless, it significantly decreased $(p=0.026)$ circulating MDSCs. The insufficient anti-tumor efficacy of the short peptide vaccine may be due to deficiency in activating $\mathrm{CD}^{+}$helper $\mathrm{T}$ cells that are often required to support the $\mathrm{CD} 8^{+} \mathrm{T}$ cells as shown in several studies. ${ }^{894344}$ Indeed, vaccination with elongated peptides (by addition of natural flanking sequences) significantly increased the anti-tumor efficacy $(\mathrm{p}=0.0001)$. Additionally, long peptide vaccination elicited stronger $T$ cell responses characterized by increased percentages of polyfunctional specific $\mathrm{CD}^{+}$and $\mathrm{CD}^{+}{ }^{+} \mathrm{T}$ cells. Furthermore, long peptide vaccination enhanced the infiltration of $\mathrm{CD} 4^{+} \mathrm{T}$ cells into the tumors. It is known that $\mathrm{CD} 4^{+} \mathrm{T}$ cells can license DCs via CD40-CD40L interaction, which enhances antigen presentation to and activation of $\mathrm{T}$ cells. ${ }^{45}$ It may also be possible that $\mathrm{CD}^{+} \mathrm{T}$ cells themselves kill tumor cells. ${ }^{4346}$ Probably more important is that tumor growth is inhibited by pro-inflammatory milieu generated by the effector cytokines, such as IFN- $\gamma$ and TNF- $\alpha$, which are not only released by $\mathrm{CD} 8^{+} \mathrm{T}$ cells but also by $\mathrm{CD} 4^{+} \mathrm{T}$ cells. However, despite the dependence on $\mathrm{CD} 4^{+} \mathrm{T}$ cells, the anti-tumor efficacy remained critically dependent on $\mathrm{CD} 8^{+} \mathrm{T}$ cells as shown by strongly reduced protection on in vivo depletion of $\mathrm{CD} 8^{+} \mathrm{T}$ cells.

There is general agreement that $\mathrm{T}$ cell vaccines must become more potent, particularly for the induction of $\mathrm{CD}^{+} \mathrm{T}$ cell responses, in order to increase the likelihood of clinical benefit. However, while $\mathrm{CD} 4^{+} \mathrm{T}$ cell responses are readily induced by the currently used cancer vaccines (eg, RNA, or free peptides mixed with adjuvants), $\mathrm{CD} 8^{+} \mathrm{T}$ cell responses induced by the majority of vaccines remain relatively scarce, ${ }^{45}$ particularly when vaccine antigens must undergo processing and cross-presentation by DCs which is an important but relatively inefficient process. Conversely, the requirement for cross-presentation has the advantage that only DCs present the vaccine's MHC-I antigens to $\mathrm{CD}^{+} \mathrm{T}$ cells, favoring robust $\mathrm{T}$ cell priming and boosting, and avoiding tolerance induction. ${ }^{47}$

Immunosuppressive mechanisms are often responsible for the inefficiency of immunotherapy. Some of those mechanisms may be successfully hindered by therapies that appropriately activate $\mathrm{T}$ cell responses. Indeed, our long peptide vaccine led to significant reduction within 
tumors of granulocytic MDSCs known to exert negative effects on T cells, whereas appropriately activated T cells produce IFN- $\gamma$ that counteracts MDSCs. ${ }^{48}$ These two cell populations may also be used as biomarkers for predicting treatment efficacy.

Surgical resection is usually the first step in the clinical management of cancer. Subsequently, residual microtumors as well as circulating cancer cells may cause potentially lethal recurrence. ${ }^{49}$ Immunotherapy is particularly necessary and potentially useful in patients who are at risk for subsequent disease recurrence and progression. Checkpoint blockade is often used in this setting. Alternatively, or in addition, personalized cancer vaccines may be considered, as they have the potential to activate the immune system more specifically and may thus have a favorable efficacy/toxicity profile, provided that they achieve sufficient anti-tumor effects for providing clinical benefit. This can be well addressed in the 4T1 tumor model, because these tumors can spontaneously metastasize from primary lesions to lymph nodes, lung, brain and bone, resembling triple-negative stage IV human breast cancer. ${ }^{50}$ After surgical resection of the primary tumors, we found that our multi-NeoAG vaccine led to reduction of tumor recurrence and metastases formation. Therefore, the use of our vaccine in this setting may be promising.

Vaccination alone may be insufficient to achieve satisfactory tumor control ${ }^{51}$ calling for combination therapies. For example, we and others have shown previously that combining a multitargeting vaccine with anti-CD25 $\mathrm{mAb}$ treatment to inhibit regulatory $\mathrm{T}$ cells significantly improved the anti-tumor efficacy in challenging mouse tumors. ${ }^{2152}$ We envision that combining our new vaccine with anti-CD25 mAb, anti-OX40 $\mathrm{mAb}$ and/or checkpoint inhibitors may further improve therapy efficacy. The identification of patient-individual NeoAG remains challenging but is technically feasible. ${ }^{27} 53$ Together, our approach represents a further step making the vision of personalized cancer vaccines more realistic. Clinical development is encouraged because the vaccine induces efficient anti-tumor responses and is practically feasible as it can be formulated at bedside and may, therefore, be broadly applied.

\section{Author affiliations}

${ }^{1}$ Department of Medical Oncology, Hamad Medical Corporation, Doha, Qatar ${ }^{2}$ Department of BioMedical Research, University of Bern, Bern, Switzerland ${ }^{3}$ Department of Oncology UNIL CHUV, University of Lausanne, Epalinges, Switzerland ${ }^{4}$ Department of Oncology, University Hospital of Lausanne, Lausanne, Switzerland ${ }^{5}$ Ludwig Institute for Cancer Research, Lausanne Branch, Lausanne, Switzerland ${ }^{6}$ Swiss Institute of Bioinformatics, Lausanne, Switzerland

${ }^{7}$ University of Bern, Bern, Switzerland

${ }^{8}$ Department of Medical Oncology, National Center for Cancer Care and Research, Doha, Qatar

${ }^{9}$ Department of Oncology, Centre Hospitalier Universitaire Vaudois, Lausanne,

Switzerland

${ }^{10}$ University of Lausanne, Lausanne, Switzerland

${ }^{11}$ Nuffield Department of Medicine, University of Oxford, Oxford, UK
Contributors Design of experiments, acquisition of data, interpretation and analysis of data: MOM, DES, SdB and MFB. Whole exome sequencing and mass spectrometry-based identification of neoantigens: MB-S, JM, HP, BJS and GC. Writing, revision and editing of manuscript: MOM, DES, MB-S and MFB. Technical, material and tool support: VPI, MV and SD. Study supervision: MOM and MFB. All authors read and approved the final manuscript.

Funding This work was supported by Qatar National Research Fund (PDRA40118-18002) and Swiss Cancer Research (KFS-4291-08-2017-R and KFS-524602-2021-R). The graphical abstract, Figure $1 \mathrm{~A}$, Figure $3 \mathrm{~A}$ and Figure $5 \mathrm{~A}$ were generated with BioRender.com.

Competing interests MM, DES and MFB are shareholders of DeepVax GmbH, involved in the development of cancer immunotherapy.

Patient consent for publication Not applicable.

Ethics approval This study does not involve human participants.

Provenance and peer review Not commissioned; externally peer reviewed.

Data availability statement Data are available upon reasonable request.

Supplemental material This content has been supplied by the author(s). It has not been vetted by BMJ Publishing Group Limited (BMJ) and may not have been peer-reviewed. Any opinions or recommendations discussed are solely those of the author(s) and are not endorsed by BMJ. BMJ disclaims all liability and responsibility arising from any reliance placed on the content. Where the content includes any translated material, BMJ does not warrant the accuracy and reliability of the translations (including but not limited to local regulations, clinical guidelines, terminology, drug names and drug dosages), and is not responsible for any error and/or omissions arising from translation and adaptation or otherwise.

Open access This is an open access article distributed in accordance with the Creative Commons Attribution Non Commercial (CC BY-NC 4.0) license, which permits others to distribute, remix, adapt, build upon this work non-commercially, and license their derivative works on different terms, provided the original work is properly cited, appropriate credit is given, any changes made indicated, and the use is non-commercial. See http://creativecommons.org/licenses/by-nc/4.0/.

\section{ORCID iDs}

Mona 0 Mohsen http://orcid.org/0000-0003-3510-9148

Said Dermime http://orcid.org/0000-0002-5526-7496

\section{REFERENCES}

1 Hacohen N, Fritsch EF, Carter TA, et al. Getting personal with neoantigen-based therapeutic cancer vaccines. Cancer Immunol Res 2013:1:11-15.

2 Keskin DB, Anandappa AJ, Sun J, et al. Neoantigen vaccine generates intratumoral $\mathrm{T}$ cell responses in phase $\mathrm{lb}$ glioblastoma trial. Nature 2019;565:234-9.

3 Liu CJ, Schaettler M, Blaha DT, et al. Treatment of an aggressive orthotopic murine glioblastoma model with combination checkpoint blockade and a multivalent neoantigen vaccine. Neuro Oncol 2020;22:1276-88.

4 Ott PA, Hu Z, Keskin DB, et al. An immunogenic personal neoantigen vaccine for patients with melanoma. Nature 2017;547:217-21.

5 Sahin U, Derhovanessian E, Miller M, et al. Personalized RNA mutanome vaccines mobilize poly-specific therapeutic immunity against cancer. Nature 2017;547:222-6.

6 Chen X, Yang J, Wang L, et al. Personalized neoantigen vaccination with synthetic long peptides: recent advances and future perspectives. Theranostics 2020;10:6011-23.

7 Rabu C, Rangan L, Florenceau L, et al. Cancer vaccines: designing artificial synthetic long peptides to improve presentation of class I and class II T cell epitopes by dendritic cells. Oncoimmunology 2019;8:e1560919.

8 Borst J, Ahrends T, Bąbała N, et al. 4(+) T cell help in cancer immunology and immunotherapy. Nat Rev Immunol 2018;18:635-47.

9 Hunder NN, Wallen $\mathrm{H}$, Cao J, et al. Treatment of metastatic melanoma with autologous CD4+ T cells against NY-ESO-1. N Engl J Med Overseas Ed 2008;358:2698-703.

10 Calvo Tardón M, Allard M, Dutoit V, et al. Peptides as cancer vaccines. Curr Opin Pharmacol 2019;47:20-6.

11 Santos PM, Butterfield LH. Dendritic cell-based cancer vaccines. J Immunol 2018;200:443-9.

12 Fiedler K, Lazzaro S, Lutz J. mRNA cancer vaccines. Recent Results Cancer Res 2016;209:61-85. 
13 Cawood R, Hills T, Wong SL, et al. Recombinant viral vaccines for cancer. Trends Mol Med 2012;18:564-74.

14 Ribas A, Dummer R, Puzanov I, et al. Oncolytic virotherapy promotes intratumoral T cell infiltration and improves anti-PD-1 immunotherapy. Cell 2018;174:1031-2.

15 Mohsen MO, Augusto G, Bachmann MF. The 3Ds in virus-like particle based-vaccines: "Design, Delivery and Dynamics". Immunol Rev 2020;296:155-68.

16 Mohsen MO, Speiser DE, Knuth A, et al. Virus-Like particles for vaccination against cancer. Wiley Interdiscip Rev Nanomed Nanobiotechnol 2020;12:e1579.

17 Speiser DE, Schwarz K, Baumgaertner P, et al. Memory and effector CD8 T-cell responses after nanoparticle vaccination of melanoma patients. J Immunother 2010;33:848-58.

18 Goldinger SM, Dummer R, Baumgaertner P, et al. Nano-particle vaccination combined with TLR-7 and -9 ligands triggers memory and effector CD8(+) T-cell responses in melanoma patients. Eur $\mathrm{J}$ Immunol 2012;42:3049-61.

19 Maeyama J-ichi, Takatsuka H, Suzuki F, et al. A palindromic CpGcontaining phosphodiester oligodeoxynucleotide as a mucosal adjuvant stimulates plasmacytoid dendritic cell-mediated Th1 immunity. PLoS One 2014;9:e88846.

20 Braun M, Jandus C, Maurer P, et al. Virus-Like particles induce robust human T-helper cell responses. Eur J Immunol 2012;42:330-40.

21 Mohsen MO, Vogel M, Riether C, et al. Targeting mutated plus germline epitopes confers pre-clinical efficacy of an instantly formulated cancer Nano-Vaccine. Front Immunol 2019;10:1015.

22 Kozlovska TM, Cielens I, Vasiljeva I, et al. Rna phage Q $\beta$ coat protein as a carrier for foreign epitopes. Intervirology 1996;39:9-15.

23 Cielens I, Ose V, Petrovskis I, et al. Mutilation of RNA phage Q $\beta$ viruslike particles: from icosahedrons to rods. FEBS Lett 2000;482:261-4.

24 Storni T, Lechner F, Erdmann I, et al. Critical role for activation of antigen-presenting cells in priming of cytotoxic T cell responses after vaccination with virus-like particles. J Immunol 2002;168:2880-6.

$25 \mathrm{Li} \mathrm{H}$, Durbin R. Fast and accurate short read alignment with BurrowsWheeler transform. Bioinformatics 2009;25:1754-60.

26 Cingolani P, Platts A, Wang le L. Wang L, et al. A program for annotating and predicting the effects of single nucleotide polymorphisms, SnpEff: SNPs in the genome of Drosophila melanogaster strain w1118; iso-2; iso-3. Fly 2012;6:80-92.

27 Bassani-Sternberg M, Bräunlein E, Klar R, et al. Direct identification of clinically relevant neoepitopes presented on native human melanoma tissue by mass spectrometry. Nat Commun 2016;7:13404.

28 Cox J, Mann M. MaxQuant enables high peptide identification rates, individualized p.p.b.-range mass accuracies and proteome-wide protein quantification. Nat Biotechnol 2008;26:1367-72.

29 Reynisson B, Alvarez B, Paul S, et al. NetMHCpan-4.1 and NetMHCllpan-4.0: improved predictions of MHC antigen presentation by concurrent motif deconvolution and integration of MS MHC eluted ligand data. Nucleic Acids Res 2020;48:W449-54.

30 Bassani-Sternberg M, Gfeller D. Unsupervised HLA peptidome deconvolution improves ligand prediction accuracy and predicts cooperative effects in Peptide-HLA interactions. J Immunol 2016;197:2492-9.

31 Gfeller D, Guillaume P, Michaux J, et al. The length distribution and multiple specificity of naturally presented HLA-I ligands. J Immunol 2018;201:3705-16.

32 Zhang Y, Zhang G-L, Sun X, et al. Establishment of a murine breast tumor model by subcutaneous or orthotopic implantation. Oncol Lett 2018:15:6233-40.

33 Mohsen MO, Gomes AC, Cabral-Miranda G, et al. Delivering adjuvants and antigens in separate nanoparticles eliminates the need of physical linkage for effective vaccination. $J$ Control Release 2017;251:92-100.

34 Storni T, Ruedl C, Schwarz K, et al. Nonmethylated CG motifs packaged into virus-like particles induce protective cytotoxic $T$ cell responses in the absence of systemic side effects. J Immunol 2004;172:1777-85.

35 Mohsen MO, Heath MD, Cabral-Miranda G, et al. Correction to: vaccination with nanoparticles combined with micro-adjuvants protects against cancer. J Immunother Cancer 2019;7:137.

36 Lee N, Zakka LR, Mihm MC, et al. Tumour-infiltrating lymphocytes in melanoma prognosis and cancer immunotherapy. Pathology 2016;48:177-87.

37 Haanen JBAG, Baars A, Gomez R, et al. Melanoma-Specific tumorinfiltrating lymphocytes but not circulating melanoma-specific $T$ cells may predict survival in resected advanced-stage melanoma patients. Cancer Immunol Immunother 2006;55:451-8.

38 Dushyanthen S, Beavis PA, Savas P, et al. Relevance of tumorinfiltrating lymphocytes in breast cancer. BMC Med 2015;13:202.

39 Kreiter S, Vormehr M, van de Roemer N, et al. Mutant MHC class II epitopes drive therapeutic immune responses to cancer. Nature 2015;520:692-6.

40 Ebrahimi-Nik H, Michaux J, Corwin WL, et al. Mass spectrometry driven exploration reveals nuances of neoepitope-driven tumor rejection. JCl Insight 2019;5 doi:10.1172/jci.insight.129152

41 Baskin JM, Prescher JA, Laughlin ST, et al. Copper-free click chemistry for dynamic in vivo imaging. Proc Natl Acad Sci U S A 2007;104:16793-7.

42 Dehnert KW, Baskin JM, Laughlin ST, et al. Imaging the sialome during zebrafish development with copper-free click chemistry. Chembiochem 2012;13:353-7.

43 Quezada SA, Simpson TR, Peggs KS, et al. Tumor-reactive CD4+ T cells develop cytotoxic activity and eradicate large established melanoma after transfer into lymphopenic hosts. J Exp Med 2010;207:637-50.

44 Rosalia RA, Quakkelaar ED, Redeker A, et al. Dendritic cells process synthetic long peptides better than whole protein, improving antigen presentation and T-cell activation. Eur J Immunol 2013;43:2554-65.

45 Perez SA, von Hofe E, Kallinteris NL, et al. A new era in anticancer peptide vaccines. Cancer 2010;116

46 Schumacher T, Bunse L, Pusch S, et al. A vaccine targeting mutant IDH1 induces antitumour immunity. Nature 2014;512:324-7.

47 Bijker MS, van den Eeden SJF, Franken KL, et al. CD8 ${ }^{+}$CTL priming by exact peptide epitopes in incomplete Freund's adjuvant induces a vanishing CTL response, whereas long peptides induce sustained CTL reactivity. J Immunol 2007;179:5033-40.

48 Tcyganov E, Mastio J, Chen E, et al. Plasticity of myeloid-derived suppressor cells in cancer. Curr Opin Immunol 2018;51:76-82.

49 Paik S, Shak S, Tang G, et al. A multigene assay to predict recurrence of tamoxifen-treated, node-negative breast cancer. $N$ Engl J Med 2004;351:2817-26.

50 Kaur P, Nagaraja GM, Zheng $\mathrm{H}$, et al. A mouse model for triplenegative breast cancer tumor-initiating cells (TNBC-TICs) exhibits similar aggressive phenotype to the human disease. BMC Cancer 2012;12:120

51 Accolla RS, Buonaguro L, Melief C, et al. Editorial: novel strategies for anti-tumor vaccines. Front Immunol 2019;10:3117.

52 Onda M, Kobayashi K, Pastan I. Depletion of regulatory T cells in tumors with an anti-CD25 immunotoxin induces CD8 T cellmediated systemic antitumor immunity. Proc Natl Acad Sci U S A 2019;116:4575-82.

53 Müller M, Gfeller D, Coukos G, et al. 'Hotspots' of antigen presentation revealed by human leukocyte antigen Ligandomics for neoantigen prioritization. Front Immunol 2017;8:1367. 